\title{
Graves, Gifts, and the Bereaved Consumer: A Restorative Perspective of Gift Exchange
}

\author{
Jenna M. Drenten \\ Loyola University Chicago, jdrenten@luc.edu \\ Kristy McManus \\ University of Georgia \\ Lauren I. Labrecque \\ Loyola University Chicago
}

Follow this and additional works at: https://ecommons.luc.edu/business_facpubs

Part of the Applied Behavior Analysis Commons, and the Business Commons

\section{Author Manuscript}

This is a pre-publication author manuscript of the final, published article.

\section{Recommended Citation}

Drenten, Jenna M.; McManus, Kristy; and Labrecque, Lauren I.. Graves, Gifts, and the Bereaved Consumer: A Restorative Perspective of Gift Exchange. Consumption Markets \& Culture, 20, 5: 423-455, 2017. Retrieved from Loyola eCommons, School of Business: Faculty Publications and Other Works, http://dx.doi.org/10.1080/10253866.2017.1367680

This Article is brought to you for free and open access by the Faculty Publications and Other Works by Department at Loyola eCommons. It has been accepted for inclusion in School of Business: Faculty Publications and Other Works by an authorized administrator of Loyola eCommons. For more information, please contact ecommons@luc.edu.

\section{(c) $($ () $\ominus$}

This work is licensed under a Creative Commons Attribution-Noncommercial-No Derivative Works 3.0 License. (C) Taylor \& Francis 2017 
Drenten, Jenna, Kristy McManus, and Lauren Labrecque (2017), "Graves, Gifts, and the Bereaved Consumer: A Restorative Perspective of Gift Exchange," Consumption Markets \& Culture, 20(5), 423-455.

Note: This is a preprint version. The final published version of the paper may reflect notable format and content changes.

\title{
Graves, Gifts, and the Bereaved Consumer: A Restorative Perspective of Gift Exchange
}

\begin{abstract}
When a gifting relationship is disrupted by death, why might a living consumer continue to invest in it? Consumer spending on deceased loved ones does not end with the funeral. Given the embodying power of a physical gravesite, this article examines the practice of gift giving to the deceased in the context of American cemeteries. We employ a longitudinal approach, in which 180 cemetery gravesites were photographed. The photographic data are coupled with a netnography of grief and bereavement communities. Findings support a restorative perspective of gift exchange. Bereaved consumers utilize restorative giving as a mechanism to cope with loss and maintain relationships with deceased loved ones. We outline five categories of gifts given to the deceased and present a framework of restorative giving practices. Implications are discussed in terms of identity development, symbolic communication, and reciprocity in gift giving, as deceased consumers continue to be recipients of tangible goods.
\end{abstract}

KEYWORDS: gift giving, identity, bereavement, material culture, death, rituals 


\section{INTRODUCTION}

When Katie Helms' son died at age 25 of a drug overdose, she found comfort in visiting his gravesite to leave gifts for him, such as a hand painted angel figurine. One fall day, Katie made her usual trip to the cemetery, but upon arrival, she was surprised to discover her son's angel figurine, along with the rest of his gravesite gifts, missing from his headstone. She found the items scattered on a tarp in a nearby maintenance garage and was told the cemetery now enforced a policy restricting gravesite gifts (Habegger 2015). Katie was upset by the new policy.

\footnotetext{
It sends a message that, 'Oh, this is just junky stuff. It doesn't matter,' that [the cemetery] is a business. It's a beautiful cemetery, and I'm not just, you know, officially mad at [the cemetery] or the people, but cemeteries all over are starting to not allow people to put little things. It's all we can do. I can't decorate [his] apartment. This is where we come to remember and to grieve and to heal, and it helps to be able to put things there...It's a statement to the world that I remember my loved one and that I care and that life is precious and life is fragile. (Quoted from Habegger 2015)
}

For Katie, giving these "little things" to her deceased son is a critical component of her grieving process and a symbolic representation of their ongoing relationship. Survivors feel a sense of responsibility to celebrate, honor, and memorialize their deceased loved ones through material goods (Bonsu and Belk 2003; Harper 2012; Thursby 2006; Turley and O'Donohoe 2012). As anecdotally demonstrated by Katie's experience, consumer spending on deceased loved ones does not end with the funeral as gift giving to the deceased continues long after loved ones pass away. Online retail companies like PersonalCreations.com and BereavementStore.com, offer customized cemetery gifts.

The ritual act of gifting is an interactive practice (Lowrey, Otnes, and Ruth 2004; Sherry 1983). Dominant theoretical perspectives of gift giving-social exchange, economic exchange, agapic giving, and monadic (or self) gifting-address variations in consumers' motivations for gifting. Social exchange is motivated by relational reciprocity (Ruth, Otnes, and Brunel 1999). Economic exchange is driven by status acquisition (Sahlins 1972). Agapic giving is motivated by selfless love (Belk 1996). Self-gifting is motivated by personal indulgence (Mick and DeMoss 1990; Mick and DeMoss 1992). Gifts are traditionally theorized as investments in future reciprocal relationships (Camerer 1988). When a relationship is disrupted by death, why might a bereaved consumer continue to invest in it?

Contributing to this stream of research, our study examines the practice of gift giving to the deceased in the context of American cemeteries. Given the reverence the living may hold for the dead, we might readily expect gift giving to the deceased 
to fall into an agapic paradigm - motivated by altruism, lacking reciprocity, and idealizing the beloved recipient. While we do find support for some elements of agapic giving, our data could not be fully explained by this form of selfless gifting. Our findings suggest a new perspective of gift exchange-restorative giving-a unique gift giving practice integrating elements of social, agapic, and monadic gift systems. Restorative giving is symbolically binding (i.e., social exchange) and personally communicative (i.e., monadic or self-gifting) but without concrete expectations of reciprocity (i.e., agapic giving). Restorative giving creates a tangible way for bereaved consumers to cope with their personal loss while enabling symbolic and evolving relationships with the deceased.

We begin by reviewing two important literature streams: the role of material objects in coping with bereavement and theoretical perspectives of gift giving rituals. Next, we outline our longitudinal approach to data collection and analysis, in which 180 cemetery gravesites were photographed and analyzed between 2008 and 2015 . We marry this data with evidence from an accompanying netnography of message boards and online communities centered on coping with grief and bereavement. Based on findings from the data, we offer a framework for understanding restorative giving practices in the context of ritualized occasions. Namely, we outline five categories of gifts given to the deceased (e.g., characteristic, connective, customary, decorative, and symbolic), consider each category in terms of identity orientation, discuss temporal delimiters of restorative giving, and identify social factors influencing restorative giving. Finally, we discuss the broader implications of restorative giving in relation to traditional gifting perspectives and contributions to our understanding of death and consumption.

\section{COPING WITH DEATH IN CONSUMER CULTURE}

Coping with bereavement is a personally varied and culturally complex process (Bowlby 1980; Bonanno and Kaltman 1999; Stroebe et al. 2001). Following the death of a loved one, a person experiences bereavement, which according to Mental Health America (2008), literally means "to be deprived by death." Traditional theories of coping suggest the grieving process is linear and delimited (Stroebe 1992). That is, a bereaved person can "get over it" and "move on," through hard work (Stroebe and Schut 1999). This perspective disregards the complexity of secondary stressors that accompany the loss of a loved one, such as developing new identities and attending to life's changes (Stroebe and Schut 1999). For example, a husband coping with the loss of his wife is not only grieving the loss itself, but he is also experiencing bereavement through negotiating a new identity as a widower and potentially taking on his wife's roles and responsibilities (e.g., finances, childrearing, cooking). Bereaved 
individuals are in a liminal stage. They yearn for the past through activities such as looking at old photos of the deceased and imagining how he or she would react to events; yet they operate in the present, seeking a new sense of normalcy (Gentry, Kennedy, Paul, and Hill 1995a; Metcalf and Huntington 1991).

Consumption can lead to functional coping when consumers are faced with a life-changing crisis (Baker, Gentry, and Rittenburg 2005; Moschis 2007; Pavia and Mason 2004). Material goods and experiences "embed the individual in the world of life, distract, soothe, and challenge" (Pavia and Mason 2004, p. 453). Material goods are particularly salient for bereaved consumers (Hallam and Hockey 2001). Post-death consumption practices allow the living an alternative and healthy way to deal with grief by continuing to live with their loved ones (Vickio 1999) instead of letting go completely (O'Donohoe and Turley 2005). Memories of deceased loved ones are preserved and socially constructed through material objects, such as inherited jewelry and family photographs (Gentry et al. 1995a; Hallam and Hockey 2001; Turley and O'Donohoe 2012). Riches and Dawson (1998) find bereaved parents use photographs and other material objects as 'social props' to preserve their children's social presence and guard their own parental identities. In line with Belk's (1988) extended self, leftbehind material objects (e.g., clothing, jewelry, furniture, and household goods once owned by the deceased) permanently retain the identity of their owners (Hockey and Draper 2005) and symbolically maintain a relationship between the deceased and the bereaved (Gibson 2008; Valentine 2008).

On a large scale, in the wake of public tragedy, mourners construct temporary spontaneous memorials, serving as mechanisms to express and manage grief (Doss 2008; Levy 2015; Radford and Bloch 2015). Ordinary places transform into sacred communal grieving sites where material gifts in the form of flowers, teddy bears, cards, and other mementos are placed. Instances of such mass-scale memorials include an estimated 15,000 tons of flowers and other items left at London's Royal Palace for Princess Diana, approximately 200,000 items left for victims of the shooting at Columbine High School, and close to one million items left on the Memory Fence circling the Murrah Federal Building in Oklahoma City (Doss 2008). When faced with loss, bereaved consumers use material goods to express their sorrow and symbolically honor the deceased. Acts such as gift giving and the creation of memorials are evidence of a desire for remembrance and continuation of social bonds, as opposed to the desire and expectation to find "closure" and "move on" after the death of a loved one (Levy 2015).

Previous research on death and material goods primarily investigates the disposition of possessions at the end-of-life (Bradford 2009; Lastovicka and Fernandez 2006; Price, Arnould, and Curasi 2000), objects left behind by the deceased (Turley and O'Donohoe 2012), and items presented to the deceased at the time of their death 
(Bonsu and Belk 2003; Harper 2012). For instance, in Ghana, the living give "one last gift" to deceased loved ones at their funerals in an attempt to raise their social status within the community, while alleviating feelings of guilt and grief (Bonsu and Belk 2003). In contrast, our study seeks to understand postmortem gift giving practices beyond one last gift. To date, few studies have investigated practices in which the deceased continue to be recipients of material goods (see Francis, Kellaher, and Neophytou 2005). The dearth of research on the deceased as consumers may not be surprising given their physical intangibility; however, Hockey and Draper (2005) argue the grave itself can be considered an embodiment of the deceased. Graves act as a form of cultural communication (Reimers 1999) and represent a physical space at which mourners cope with their loss (Hayslip, Jr. and Peveto 2005). Throughout history, funerals have been an impetus for presenting material objects, or "grave goods," including clothing, jewelry, food/drink, letters, and photographs (Harper 2012; Pearson 1999). According to Pearson (1999), "grave goods may include items which were possessions of the deceased, or they might be mourners' gifts to the dead" (p. 8). Previous research on grave goods is limited in that it only examines tangible gifts to the deceased at the time of their death. Given the embodying power of gravesites, the qualitative work on which this article is based suggests the deceased continue to be recipients of material gifts long after their deaths.

\section{GIFT GIVING PERSPECTIVES}

Gifts are tangible expressions of the strength and nature of the interpersonal relationships (Klein, Lowrey, and Otnes 2015; Shurmer 1971). The ritual act of gifting is not merely an action, but an interaction between multiple parties (e.g., individuals, organizations; Lowrey, Otnes, and Ruth 2004). Gifts can be used to reflect social integration into a group and establish social distance (Sherry 1983). They create the ability to affirm, strengthen, weaken, or even dissolve relationships (Ruth, Otnes, and Brunel 1999). Traditional gift giving literature centers on dyadic gift giving (Belk 2010); however, scholars increasingly acknowledge the multidimensional and complex nature of gift giving systems (Giesler 2006; Mick and DeMoss 1990; Weinberger and Wallendorf 2012).

The exchange of gifts is a means of social communication among individuals (Mick and DeMoss 1990) and can be used to construct and reinforce social identities of both the giver and receiver (Grainger 1998). Belk (2010) suggests gift giving and commodity exchange are often used interchangeably, despite fundamental differences. For instance, Giesler's (2006) perspective of gift systems, in the context of person-to-person music file sharing, may more accurately reflect a sharing economy. For our study, we borrow Belk and Coon's (1993) definition of a gift as a "good or 
service (including the giver's time, activities, and ideas) voluntarily provided to another person or group (Belk 1979) through some sort of ritual presentation" (p. 394). The ritual described in traditional gift giving systems comprises three key characteristicsthe obligation to give, the obligation to receive, and the obligation to reciprocate (Mauss 1954). Dominant theoretical perspectives of gift giving vary in the extent to which each of these characteristics manifests, particularly with regard to reciprocity.

Social and economic gift exchange models argue reciprocity is a fundamental motive of gift giving (Ruth, Otnes, and Brunel 1999; Sahlins 1972). The norm of reciprocity creates a continuous transaction cycle in which individuals are obliged to give, receive, and repay (Belk 1979; Mauss 1954). As Sherry (1983) notes, the goal, over the long-term, is to achieve balance in a given gifting relationship as unbalanced gifting relationships can create tension (Belk 1976). The death of a loved one disrupts gift rituals once shared with that person. In their study of Christmas gift traditions, Lowrey, Otnes, and Ruth (2004) suggest deceased loved ones exhibit third-party influence on the gifting practices shared among their surviving family members. For example, in their data, one informant, Beth, reenacts her mother's gift tradition of buying ketchup for Beth's husband. Beth wraps the ketchup in the way her mom would have and even signs the card with her mom's name. Consumers, like Beth, cope with disrupted gifting rituals by reenacting or relinquishing gift traditions once performed by the deceased. Lowrey, Otnes, and Ruth's (2004) research begins to address how consumers "remember or even keep alive absent loved ones" through gifting (p. 551); yet, their study is limited by viewing a deceased loved one as a thirdparty in a gifting relationship. Our study seeks to build on this research by considering a deceased loved one as an active part of the gifting dyad and the direct recipient of tangible gifts.

Social and economic models are primarily built upon assumptions of dyadic gift practices (i.e., an exchange between two parties). In contrast, Mick and DeMoss (1990) suggest monadic gifting (or self-gifting) can occur when a consumer is both the giver and receiver of a gift. In the context of self-gifting, reciprocity occurs as consumers justify their indulgences through self-bargaining (e.g., self-compensation for a hard day at work, motivational rewards; Mick and DeMoss 1990). Consumers may self-gift for therapeutic reasons (e.g., to alleviate stress, to cope with change) and self-gifting practices are often triggered by special occasions or during liminal stages (Mick 1996; Mick and DeMoss 1990; Mick and DeMoss 1992). We may expect that the therapeutic elements that may result from monadic gifting may also motivate gift giving to the deceased; however, in action, the recipient of the gifted object is the deceased person, not the giver. Thus, the behavioral performance of giving tangible gifts to the deceased cannot be explained by self-gifting. 
Self-gifts are self-interested and are often characterized as indulgent splurges (Mick 1996). In contrast, agapic giving is devoid of self-interest and is instead motivated by other-centered love (Belk 1996). Agapic giving is obligation-free and stands as an exception to Maussian expectations of reciprocity (Belk 1996; Belk and Coon 1993). Arguably, gift giving to the deceased closely follows an agapic giving model-motivated by sacrifice, lacking reciprocity, and venerating the beloved recipient. However, an emphasis on agapic, selfless giving may fail to capture identityoriented motives in gift giving, particularly during difficult life events (Klein, Lowrey, and Otnes 2015). Recent research calls for more scholarship on the role of gift giving during emotionally challenging, anxiety-laden life experiences (Klein, Lowrey, and Otnes 2015; Marcoux 2012; Weinberger and Wallendorf 2012). In line with this work, we investigate gift giving practices in which cemetery visitors (i.e., friends of the deceased, surviving family members) use gravesites as physical proxies for giving tangible gifts to the deceased, long after their death. Most theoretical perspectives of ritual (e.g., Durkheim 1915; van Gennep 1960) suggest the gravesite is a product of a rite of passage; however, our study views the cemetery as a site of ongoing, dynamic ritual performance. Examining gift giving to the deceased seeks to uncover new insights regarding materiality and reciprocity in gift giving, as the recipient (e.g., deceased loved one) is no longer physically able to consume a gift or give one in return.

\section{METHOD}

To study gift giving to the deceased, we employ an interpretive analysis of both textual and visual data. We blend traditional ethnography with supporting evidence from netnography in a dual methodological approach, in which all data were compiled and analyzed in a constant comparative method (see Glaser and Strauss 1967). First, a traditional ethnographic approach (see Wolcott 1994) guided data collection, analysis, and interpretation, allowing us to capture the meaningful nature of gift giving to the deceased. Methods include extended observations and photograph analysis of American cemeteries. Second, a netnographic approach (see Kozinets 2002, 2009) guided data collection, analysis, and interpretation. Message boards and online communities related to grieving and coping were selected as data collection sites.

\section{Extended Observations and Photograph Analysis}

Ethnographic data collection at cemetery sites utilized two complementary longitudinal methods: extended observations and photograph analysis. Over an 8-year period, from 2008 to 2015, we conducted intermittent observational fieldwork by 
observing and photographing headstones from six large American public cemeteries in three Southeastern states and two Midwestern states. These six cemeteries were visited multiple times in order to observe if and how gift-giving practices to specific gravesites endured over time. Individual gravesites were selected through observation; specifically, we walked through each cemetery, stopping at graves visually deemed as containing gifts. Guided by Belk and Coon's (1993) definition of a gift, we identified gifts as goods and services voluntarily exhibited at the gravesite; this included tangible objects (e.g., knickknacks, figurines, balloons, letters) and services (e.g., decoration of the grave for special occasions). The majority of headstones photographed were upright or lawn-level markers. One mausoleum is also included in the data. Extended observations allowed us to systematically record burial environments and artifacts placed on headstones, on each occasion and over time (Creswell 1998; Wolcott 1994).

Observations throughout the 8-year period were concentrated in the months of December, January, and February. This range includes prominent Western gift giving holidays such as Christmas and Valentine's Day. During the 8-year period, intermittent cemetery visits also took place around other secular gift giving holidays, including Mother's Day in May and Father's Day in June. In total, 180 gravesites were photographed, resulting in a total of 483 photographs over the course of seven years. Figure 1 provides example photographs and Figure 2 demonstrates the longitudinal nature of the visual data.

Observations of actual gifts were recorded through field notes, paying careful attention not to disturb any of the headstones, gifts, or other decorations placed on the graves. The photographs and field notes were then systematically coded and analyzed. Age of the deceased at the time of death ranged from 0 (infant) to 89 years. Years since death ranged from less than 1 to 52 . As publicly accessible spaces, we did not seek permission to enter, take photographs, or transcribe notes of the gravesite observations.

Insert Figure 1 here

Insert Figure 2 here 


\section{Netnographic Observation and Analysis}

To better understand the underlying meaning and lived experience of gift giving to the deceased, we employed netnographic research methods as outlined by Kozinets $(2002 ; 2009)$. Netnography applies the methods of cultural anthropology to online communities (Kozinets 2002). Netnography allows the researchers to become immersed in the field while limiting the potentially obtrusive nature of traditional ethnography, which is important given the sensitivity of our topic. In addition, as Kozinets (2009) suggests, studying 'communities online' can provide important supporting insights because online "communications inform and relate to the wider social phenomenon, behaviors, its participants, their values or beliefs" (p.64). Thus, the netnographic data in our study serve as supporting evidence for understanding deeper meanings in gift gifting to the deceased.

Message boards and four online communities centered upon coping with death and grief were selected as data collection sites. We specifically focused on discussions and comments related to individuals' experiences with gift giving to the deceased. These data were documented via electronic journals. The data collections sites were visited on a bi-monthly basis from January 2009 to February 2016. The posting dates ranged from 2004 to 2016 . We revisited message threads pertinent to the topic to look for new posts and reviewed the site for additional threads. New posts were downloaded and added to the research journal. Since this data was not generated or guided by our research team, it is considered archival data or information gathered from pre-existing communications (Kozinets 2009).

Informants were self-selected as they posted on each community website. The discussions centered on the nature of the gifts brought to gravesites and the motivations for participating in gift giving to the deceased. All data are reported using pseudonyms, for both the informants' usernames and their loved ones' names to ensure the privacy of the informants. We followed Wolcott's (1994) ethnographic conventions for analysis and interpretation by continually moving among specific transcripts, artifacts, and the evolving data set. Relying on inferences from the data and using dominant gift giving theory as a guide, we iteratively developed patterned regularities in the data and a thick description of the culture and ritual of gift giving to the deceased (Creswell 1998; Wolcott 1994). Investigator triangulation was used to ensure accurate representation and reliability of the data and analysis. Using an iterative process, the data contained in the journals were read several times. With each reading, emergent themes were identified and enhanced (Glaser and Strauss 1967). To achieve informant validation, two grief community members reviewed a copy of our 
findings to verify the analysis. These informants corroborated our analysis, and no contradictory data emerged.

\section{FINDINGS}

When friends or family members die, the ritual of giving gifts to them may easily die alongside them. Our data suggest that is not the case. Instead, bereaved consumers continue gifting practices directed toward their loved ones after death they bring balloons to them for their birthdays, they write cards to them for anniversaries, and they adorn their graves with festive holiday décor. Our data are rich in demonstrating the deeply entrenched nature of gift giving rituals, even after the death of a loved one. Our findings support a unique perspective of gift exchangerestorative giving. Restorative giving incorporates elements of social, agapic, and monadic gift systems; yet it is a unique practice in which the recipient of the tangible gift cannot physically reciprocate. Bereaved consumers perform restorative giving to symbolically reaffirm relationships with deceased loved ones (i.e., social exchange), to personally cope with loss (i.e., self-gifting), and to celebrate the lives of their loved ones (i.e. agapic giving). In other words, bereaved consumers enact gift giving rituals by explicitly giving gifts to their deceased loved ones (e.g., placing a gift on a headstone), but they are motivated by the need to cope with their own personal loss-to restore what was taken from them.

Based on the data, we offer a framework for understanding restorative gift giving practices in the context of ritualized occasions. Restorative gifts take on five identity driven forms: characteristic, connective, customary, symbolic, and decorative. The materiality of restorative gifts articulates the relationship between tangible gift giving practices and consumers' intangible bereavement experiences. Additionally, the practice of restorative gift giving is influenced by temporal delimiters and social factors. Figure 3 illustrates these features of restorative giving in the context of gift giving to the deceased. Using evidence derived from the data, we will demonstrate how restorative giving creates a tangible way for bereaved consumers to cope with their personal loss while enabling symbolic and evolving relationships with the deceased. 


\section{Materiality and Identity in Restorative Gift Giving to the Deceased}

Tangible objects play a key role in how consumers construct and perform their identities (Borgerson 2005; Roster 2014). The data support our classification of tangible graveside objects as gifts, versus merely an exchange commodity (Bell 1991) or a symbolic good (McCracken 1986). In line with Belk and Coon's (1993) definition, a restorative gift is purchased for the sole purpose of voluntarily bringing it to a loved one's gravesite and relinquishing it at the gravesite, unlike self-gifts (Mick and DeMoss 1990) which are purchased and consumed by one individual. In contrast to previous work on material objects and death (e.g., Bradford 2009; Lastovicka and Fernandez 2006; Price, Arnould, and Curasi 2000; Turley and O'Donohoe 2012), gifts placed at a gravesite tend to be new objects rather than something the deceased owned or used.

Informants explicitly referred to these objects as "gifts" in their posts (e.g., "I like to take gifts to my daughter when I visit her grave") and in their discussion topic titles (e.g., "Ideas for gifts to leave at her grave?"). Bereaved consumers use the headstone or grave marker as a tangible proxy for their deceased loved ones to receive the gift. Additionally, we find support that these objects are indeed viewed as gifts by both the giver and outside observers, through mention of these practices appearing in newspapers, blogs, and other online sources (e.g., Forest Hill Cemetery: A Guide 2016, Winzelberg 1998). Our informants describe specifically purchasing gifts for deceased individuals, including shopping for the gift and presenting it to the deceased. Akin to choosing a gift for a living individual, gift givers choose gifts that they believe the deceased recipient would enjoy (e.g., "it was something a $2 \mathrm{yr}$ old would have liked on his birthday," "your grandmother would love those colors") and even ask others for gift ideas. Our netnographic and photographic analysis reveal that restorative gifts are often given on or around traditional gift-giving holidays, supporting the notion that gift giving transcends death.

Gifts that have been given to the deceased act as tangible markers, co-creating the nature of the relationship between the living and the deceased. The data suggest a primary motive for gift giving to the deceased is coping. Visiting loved ones' gravesites and presenting gifts can aid the surviving family members and friends in the coping process.

Some people visit their child's grave + bring flowers, toys, photos of living relatives, whatever. Just spend some time with their memories of the child. Some people have their LC (living children) write letters to their sibling and "send them to heaven" on balloons...it's not that good for the environment, but sometimes it helps siblings deal with grief. Some people take the day off and just spend it with themselves, being home and safe. Taking a bubble bath, eating chocolate and watching TV, whatever their comfort activity is. (Posted by Liza, 2009) 
Interestingly, and unique to the context of gift giving to the deceased, material objects are as much a reflection of the deceased as they are a reflection of the living. Hockey and Draper (2005) suggest photos of the deceased are resources for memory and imagination, allowing mourners to remember their passed loved ones favorably. In contrast, Liza mentions some bereaved parents take photographs of living relatives to their deceased children's graves. These parents are attempting to keep their deceased children connected with their family identity and living relatives. Thus, in gift giving to the deceased, material objects act as a catalyst for maintaining existing identities or developing new identities, both at an individual identity level (e.g., Goffman 1959) and at a broader family identity level (e.g., Epp and Price 2008). Previous research suggests death related rituals sustain shared memories of the past (Jonker 1997); however, our study suggests the ritual of gift giving to the deceased engenders new individual and collective identities.

I am always surprised to read other bereaved parents words, surprised at how others feel and think the same way that I do. I still often feel like I'm the only one. We have found it easiest to make new traditions in our house at Christmastime since Kali died. This is our third Christmas without her. Our season begins with bringing a tree to the cemetery for her, then it's shopping to buy toys to put under the sharing tree at the mall. I stick in a card that says that the toys are donated in memory of Kali and I buy things that she would like. (Posted by Vicki, undated)

As Vicki and her family create new traditions and customs, she takes care to include her deceased daughter Kali in the process. Vicki brings a Christmas tree to the cemetery, symbolically including Kali in their family's Christmas traditions. She buys toys her daughter would have enjoyed and donates them to other children. This push and pull between past and present are fundamental to the grieving process. Faced with the reality of losing a child, as in Vicki's case, a family uses material goods as a tangible way to remember their loved one, cope with their grief, and co-create their new individual and collective identities (e.g., Epp and Price 2008). In line with previous research on identity development during transitional phases (e.g. Andreasen 1984; Belk 1992; Klein, Lowrey, and Otnes 2015; Gentry et al. 1995a; Schouten 1991), material objects are critical to the liminal process of bereavement.

Bereaved consumers aim to restore what has been lost. The materiality of restorative gifts provides a tangible aspect to consumers' nebulous grieving experiences. For example, one respondent, Emily, discusses how she coped with a recent miscarriage after previously enduring the death of her young baby.

It seems trivial compared to losing the baby, but I just had a miscarriage. We did a Build-a-Bear, a shamrock for yesterday (the day we found out), with angel wings. We also put the name and date on the birth certificate. (Posted by Emily, 2010) 
Consumers invest their identities in "non-commodity, gift-like objects which, through their association with stories, dreams, and the transmission of skills and status, temporarily encapsulate precluded social personhood" (Parkin 1999, p. 313). Emily's experience reflects the derived value of finding comfort in symbolic material goods. After her miscarriage, she needed a way to cope with the loss and assert her seemingly lost identity as a mother. Particularly in the case of transitional periods, familiar or owned possessions act as an anchor for previously established identities (Mehta and Belk 1991). In contrast, Emily's unborn child did not have any possessions or mementos, so Emily used restorative giving to anchor her experience. Emily's miscarried baby has no physical presence (e.g., a grave), so in line with Mick (1996), Emily is the purchaser and the recipient of the gift. The shamrock and angel wings provided a symbolic way for Emily to acknowledge her loss and tangibly assert her identity, individually as a mother and collectively as a family.

Mourners use new material gifts to represent their own identities as they seek to connect with their lost loved ones. Emily's gift is highly personal as the gift reflects attributes related to the date when she learned that she had lost her unborn child, St. Patrick's Day. Our netnographic observations and photographs of cemeteries reveal a range of identity-oriented material gifts-some, like Emily's, are highly personal, and representative of the relationship bereaved consumers share with their deceased loved ones. Other gifts represent a broad, cultural identity orientation, such as a religious affiliation or performance of social norms (e.g., flowers are customary in funerary rituals).

Findings from our inquiry reveal five emergent categories of material gifts given to the deceased including characteristic, connective, customary, symbolic, and decorative. In line with Klein, Lowrey, and Otnes (2015), these categories are organized in terms of identity orientation, from relational identity orientation to cultural identity orientation. Relational identity categories reflect a deep personal knowledge of the deceased and experiential interaction (e.g., actual or imagined) between the bereaved giver and deceased receiver. For instance, a bereaved daughter knows her deceased mother loved dolphins, and they went on beach vacations together often; so, on future vacations without her mother, she brings back dolphin themed gifts to place at the cemetery. Cultural identity categories reflect a more general or broad sense of self, identifying on a cultural or social norm level. For instance, decorating a stranger's grave with flowers does not reflect a personal relationship but rather a shared collective and cultural identity.

In total, 782 items were identified in the 180 gravesites. These categories were further supported by the netnographic data. For each category, Table 1 provides definitions, exemplary photographs of material gifts, contextualized details on identity orientation, and a representative quote. In addition, Table 1 also identifies key 
external influences in each gift giving category. These influences will be discussed in more detail later in the paper. The categories of material gifts are not intended to be mutually exclusive, and some gifts may fall into multiple categories. For example, a bereaved consumer may purchase flowers to leave at a loved one's gravesite, in line with common cultural norms (e.g., cultural identity orientation). Specifically, the bereaved consumer chooses sunflowers, knowing they were the deceased's favorite and thus establishing a relational connection (i.e., relational identity orientation).

Insert Table 1 here

\section{Characteristic}

Characteristic gifts placed on and around the headstones reflect the personal interests, or lifestyles, of the deceased or the bereaved gifter. These gifts tend to reflect identity aspects of the deceased, communicating the personality of the deceased through material objects. One headstone reflected a 15-year-old girl's personal love for dolphins, with etching of the animals carved into the stone. Surrounding the headstone were other dolphin-themed items, such as a picture frame featuring a photograph of the young girl. Nearby, miniature horse figurines lined the base of a 12-year-old girl's headstone. Most often, young children's graves featured personalized mementos reflective of their lives, whereas the graves of those who had died at later stages in life did not. In fact, this was true for most gifts. It appeared that adolescents had significantly more keepsakes added to their graves. In line with previous research, characteristic gifts are an extension of the deceased' selves when they were living (Belk 1988; Gentry et al. 1995a; Hallam and Hockey 2001; Riches and Dawson 1998).

I still bring my Brother a pack of cigarettes and light one for him every time I go visit him. It's how I remember him and bring him something that I knew he enjoyed while he was alive. I don't care if someone takes them or throws them away after I've left. It matters to me and makes me feel good when I go see him. It's my way of remembering him and my way of dealing with my loss. (Posted by Nils, 2008)

What is striking about characteristic gifts, such as cigarettes, is the interactional consumption element often involved. In this example, Nils gives the cigarettes to his brother by leaving them at the gravesite. He behaviorally and symbolically lights one "for" his brother; however, Nils says he does it for himself, thus reflecting qualities that stem from monadic gifting. Nils' brother is disembodied in his death (Hockey and Draper 2005) but symbolically embodied through the ritualized action of lighting a 
cigarette and then leaving the pack at the gravesite as an offering. Even more so, characteristic gifts demonstrate how well the gift giver knew the deceased.

[It] is a sweet idea to write a message on the balloons. I think I may do that. You think it would be tacky to blow up red, yellow and green balloons, or should I just go with white and pink? My baby was always soothed by Bob Marley's music, so I was thinking reggae colors would fit her personality. (Posted by Victoria, 2009)

Victoria's deceased baby was soothed by Bob Marley music, which is also a reflection of Victoria's identity. In this way, the characteristic gift is as much a reflection of the deceased receiver as it is of the living gifter. Victoria believes white and pink balloons would also be appropriate, but these culturally gendered colored balloons would be considered less personally reflective of her daughter's identity. Characteristic gifts allow mourners to sustain their deceased loved one's identities while also actively asserting a personal knowledge of the deceased.

\section{Connective}

Connective gifts to the deceased represent an active exchange between the giver (i.e., the living) and the receiver (i.e., the deceased). That is, connective gifts are relational and communication-oriented. Some living gifters believe their gifts are actively received by deceased loved ones. Gifts, such as letters and cards, left upon gravestones are actively written and "sent" to the dead. For instance, one card at a gravesite appeared to be sealed; however, it was addressed to the person upon whose grave it had been placed. Letters, such as the Father's Day note pictured in Table 1, were weathered from withstanding the elements. These forms of tangible correspondence offer media through which bereaved consumers feel they can communicate and connect with their lost loved ones.

When my family and I visit my dad at the cemetery, we talk to him out loud as if he were standing in front of us. Then, we each place a penny on his grave and let him know it's for his thoughts. My father is really missed, and I don't think the visits will ever stop. On Father's Day, he gets flowers and candles at his gravesite as well. (Posted by Martha, undated)

Connective gifts act as a bridge between the living and deceased. Martha and her family engage in an open conversation with her deceased father when they visit the cemetery. In the absence of her father's direct response, her family members each leave a penny on the grave acknowledging his unspoken or imagined response. Bereaved consumers seek to speak to and hear from their deceased loved ones. Martha's act of placing a penny on her father's grave signals to herself and other people that he is remembered and his disembodied response is acknowledged. Connective gifts symbolically supersede the communication loop. That is, through 
connective gifts, bereaved consumers communicate with their deceased loved ones, despite lacking a direct response from them. Piles of weathered pennies were found placed on multiple graves in our study. The practice of leaving pennies is commonly perceived as an attempt to pass on good luck or prosperity to loved ones in the afterlife; however, the motivation for leaving connective gifts is to continue a relationship with the deceased.

Our daughter Melissa lost her battle with cancer July 08...the thought of spending a Christmas Eve and Christmas Day without her is unbearable. We decided to buy a tall 9 foot new tree this year and we call it our Melissa tree. Family that arrived for Thanksgiving brought their special ornament that reminded them of her. All the ornaments she collected and that were given to her since day 1 will be on the Melissa tree. I sent out invitations to all her friends to gather on a Sunday afternoon to dedicate the Melissa tree, and to bring an ornament. Her stocking is hung along with the others. From time to time I drop a note in there to express my feelings and to say love you forever. Her baby blanket is the tree skirt. This is my way of including her with us in spirit. Her ashes are on the mantel above her stocking, she is all around me I know... I find pennies very often, especially after a tough day emotionally...she is trying to say, don't be sad! (Posted by Sharon, undated)

Sharon's daughter, Melissa, was cremated. The lack of a gravesite does not prevent Sharon from enacting gifting rituals, particularly in the category of connective gifts. The notes Sharon drops in Melissa's stocking are direct attempts to communicate symbolically. Sharon then perceives a response to occur when she comes across pennies. The effect of such gifts can also extend beyond the giver to other mourners.

Every time I and some of his other friends \& family visit the cemetery or the memorial, we leave a coin. It is kind of like a calling card, saying you've been there and that you were remembering him. It has been almost 6 years and it somehow makes me feel better stopping by his headstone and still seeing new coins appear because someone was still thinking of him and wishing he was with us. (Posted by Sarah, 2008).

Gifts like these allow network ties to be perpetuated and strengthened, even in the absence of a loved one. Such connective gifts have similarity to what Lowrey, Otnes, and Ruth (2004) describe as enacting third party traditions, where the connections to the deceased loved one are kept alive through the actions of a family member taking over a gift giving tradition of the deceased. Through such gifts, third parties play a role in gift exchange (Lowrey, Otnes, and Ruth 2004). While their gifts are meant for the deceased, they also become "calling cards" to others that signal that others had visited and remembered the deceased. 


\section{Customary}

Customary gifts to the deceased are embedded in a larger cultural context and driven by traditional holidays or special events. Living friends and family members seek a way to maintain normalcy and adapt to holiday seasons without their deceased loved ones. Many headstones displayed trinkets of holiday seasons, such as Christmas, Valentine's Day, birthdays, and anniversaries. For instance, a child's drawing with the words "Happy Father's Day" was placed on the headstone of a male who passed away in his mid-thirties. A small teddy bear with a "Happy Birthday" t-shirt on it was placed on another headstone of a young girl, only 20 years old at the time of her death; however, her birthday was nearly six months earlier. Many gift givers, such as Acksherly below, describe the importance of keeping connections with their deceased loved ones through the holidays through choosing gifts specifically designed for holidays.

I am sorry to hear of your loss. You are a sweet son to leave little gifts! We leave figurines...for example, around Easter...we put glass bunnies....Christmas, always a Poinsetta or a small Christmas tree. There are always some type of figurine or little statue that goes with the season/holiday... (Posted by Acksherly, 2006)

\section{Symbolic}

Symbolic material gifts are representative of a larger cultural identity, such as a religious belief system or ideology. For instance, gravesites featured symbols that have traditionally been associated with faith and spiritually, such as angels and crosses. One motive behind symbolic gifting may be to symbolically elevate the status of a deceased individual (Bonsu and Belk 2003). Symbolic gifts are different than customary gifts in that symbolic gifts reflect a broad ethnic, cultural, religious, or ideological identity versus a specific holiday or ritualized occasion. For instance, in Judaism, common practice ascribes placing a stone on the grave to symbolize the permanence of memory (Riemer 1995).

I always had a vague idea that [placing stones on graves] was a Jewish tradition and yet my family who is Catholic has placed pebbles on the grave markers of loved ones for some time and I've seen them sitting atop other markers in Catholic cemeteries, too! Maybe it's creeping into popular custom as well. It always perks me up a bit when I visit a loved one's grave and find more stones there than the last time I visited. I make sure to bring one pebble for each person I'm visiting. Also the (non Jewish) cemeteries seem to have a sense of what we're doing because I've never seen any of the pebbles removed. (Posted by Joe, 2008) 
Symbolic graveside gifts point toward a collective identity (e.g., Reimers 1999). Symbolic gift giving practices are motivated by learned behavior on the part of the gifter and cultural identity reflective of the deceased. American patriotic symbols such as miniature American flags and bald eagle figurines were also prominent on the headstones. Most often, the graves featuring tokens of patriotism were often clearly denoted as former members of the military. While both characteristic and symbolic gifts signal aspects of the deceased's identity, the key difference is that symbolic gifts are representative of a larger cultural identity (e.g., religion, military status) whereas characteristic gifts are related to the personal interests or lifestyle of the deceased. Akin to the funerary practices described by Bonsu and Belk (2003), symbolic gifts can be used to renegotiate the deceased's identity.

There are some pretty wild displays in this cemetery, so our low-key offerings pale in comparison. One grave is just SURROUNDED by little angel statues and even a couple of lawn ornaments. It's the tackiest thing I've ever seen. The funny thing is that while it looks like this woman was well-loved and is greatly missed... I guess she was a pretty nasty piece of work that's been elevated to sainthood since her passing. Her kids that still live nearby do "drive by" visits -- they just drive to the stone (which faces a drive), pause for a few moments, and move on. (Posted by Kathy, 2008).

In many cases, illuminated crosses and angels were placed beside the headstones; however, as Kathy notes, angels are not always characteristic of the actual personality a deceased person had in reality. In Kathy's case, the angels surrounding the headstone are more reflective of a symbolic identification with the afterlife and the religious connotations that the deceased woman's children hope to portray to observers rather than a reflection of the deceased's character. Here the positive associations with angels elevate the deceased's identity regarding the "goodness" of her character and her religiousness.

\section{Decorative}

Decorative gifts merely serve as ornamental pieces to aesthetically "dress up" the gravesite. Decorative material gifts including items such as flowers, planters, garden statues, and wind chimes. The primary focus of these items is aesthetic and one may argue that these gifts may frequently be for not only the deceased but also for their visitors. It is likely that some of these items also fall under another category of materiality. For instance, a grieving consumer may have left flowers as a gift to a deceased loved one for a birthday (i.e., a customary material gift) or a garden statue may have been given to a loved one who was an avid gardener (i.e., a characteristic material gift). Given the nature of our photographic data, we are unable to verify gift givers' intentions underlying each specific material object; however, our netnographic 
data supports the notion that some gifts are merely for ornamentation. Just as consumers might embellish their homes, graves act as a physical site for enacting decoration practices on behalf of the deceased.

My son has 3 stones with sayings on them, he gets flowers that match the seasons cause he has a built in vase on his headstone, a teddy bear, a stuffed bunny for Easter, a wooden cross that his 11 year old uncle (my brother) made, some solar lights and that's it for now... I always try to leave him things when I can! (Posted by MiMi, 2010)

Driven by cultural aesthetics, flowers are the most common, and acceptable, decorative gift. As MiMi mentions, her son's headstone features built-in vases. In our data, permanent vases were common features of headstones. Thus, before loved ones are even buried, headstone design decisions are made with the intention of placing flowers in built-in vases. If the deceased selected their headstones prior to death, this could be a way to partially guarantee their living loved ones would visit their graves and adorn their headstones. Interestingly, some permanent vases sat empty. This could be due to the costs associated with purchasing flowers, season after season.

Decorative gifts are largely motivated by social norms and cultural expectations. For instance, in Catholic countries in Southern Europe, an image of the deceased is commonly featured on the headstone itself; in Sweden, lights and lamps are often found adorning gravesites (Reimers 1999). Our netnography uncovered a disdain for certain gifts that were described as unappealing and lacking good aesthetic taste.

\footnotetext{
Aesthetics -- which is why people leave flowers. Stuffed Spongebob and Happy Meal toys, not pleasing to anyone, especially the deceased because the living will appreciate having (not seeing) them more. (Posted by Jim, 2009)
}

Throughout our data, debate over which types of gifts are considered "acceptable" emerged often. We further discuss aesthetic social comparison and expectations later in our findings; however, as a category of material gifts, decorative objects are driven by culture and society. As Jim notes, flowers are aesthetically pleasing and acceptable. Other material objects are perceived as aesthetically unappealing. Moreover, Jim believes gratuitous adornments are wasted on the deceased, given they cannot actually use them. Toys, for instance, would be more appropriately gifted to living children. His perspective perfectly illustrates the variations in gift giving to the deceased and the contrast between gifts that are representative of more personal, relational identity (e.g., characteristic of the deceased) versus gifts that are representative of more broad, cultural identity (e.g., decorative flowers as a cultural norm). 
Collectively, the primary thread tying all five categories of gifts together lies in the tangibility and materiality of the gifts given to the deceased. As individuals, the deceased no longer exist in the physical world; however, their gravesites provide a physical space upon which material gifts can be left. Besides a means to show respect for the deceased, the ritual of gift giving to the deceased can be regarded as a tool to cope with death-maintaining the relationship with the deceased. A gift for the deceased acts as a mechanism of identity maintenance and development, on a spectrum from personal relational identity to broad cultural identity.

Gifts can be used to construct and reinforce social identities of both the giver and receiver, which is akin to Ghanaian funerary practices described by Bonsu and Belk (2003). However, the main distinction between the material consumption practices described by Bonsu and Belk (2003) is that these items are purchased and displayed for a specific moment in time, the funeral, and are strategically presented to an anticipated public audience in this one-time event. Gifts left on cemetery plots for the deceased are not bound to a specific ritual or event. Here, the dead continue to amass gifts over a period of years, with no definite anticipation of who will see these gifts. Both, however, allow the relationship between the bereaved and the deceased to continue after death. We further describe the contextual and temporal factors that influence gift giving and discuss how these impact the how these material objects play a role in the grieving processes in the proceeding sections.

\section{Context of the Ritualized Occasion}

Gift giving rituals traditionally center on celebratory occasions, such as religious holidays and birthdays (Otnes and Lowrey 2004; Sherry 1983). The same is true for gift giving to the deceased. For instance, consumers may give gifts to their deceased loved ones for holidays, which were celebrated while the loved one was living, such as Christmas or the deceased's birthday. Beyond traditional or personal holidays, gift giving to the deceased is an ongoing process, often practiced on an ad hoc basis. The context of a ritualized occasion motivates and often determines the material gift given to the deceased. Consumers give gifts to the deceased to mark a special occasion (e.g., religious holiday, anniversary) or "just because" (e.g., thinking of you). Based on the data, holidays appear to be more the allenging than other times of year. The respondents often spoke of the "firsts": the first Thanksgiving without a loved one, the first Christmas without a loved one, the first birthday without a loved one, and the first anniversary of a loved one's death.

I go [to the cemetery] often during the year, but during the holidays, for some reason I feel more inclined to go and feel more of a connection with my mom and [my daughter] Angela. I go to great efforts to have their graves looking really nice and in the evenings 
during special occasions, I try to keep candles burning at the grave. This Christmas will be our first Christmas without Mom. We'll miss her so much, along with [my daughter]

Angela. (Posted by Susan, 2004)

Surviving loved ones find symbolic ways (e.g., lighting a candle) to celebrate holidays while simultaneously acknowledging their deceased loved ones' lives. In the case of shared cultural or religious holidays, bereaved consumers, like Susan, even go as far as maintaining and decorating other graves in the area.

The deceased and the bereaved become anchored to enduring ritualized contexts, which are expected to persist, regardless of the demise of singular participants. In other words, the ritualized contexts (e.g., holidays, special occasions) continue, despite the loss of a loved one. Thus, gift giving to the deceased transcends grief as the ritual context persists. Collective holidays continue to exist. Despite the challenges bereaved consumers face, particularly around ritualized gift giving holidays, they continue to enact gift giving rituals associated with each event. For instance, Hannah, a mother of five sons, discusses how she handles celebrating the birthday of her living son Jacob, whose twin brother Jordan passed away.

Well, [my situation] is a little different than most. Jordan has a twin, Jacob. On their birthday we go to the cemetery with balloons (one for each person and a couple for his grave) and a cookie cake (Jordan was 5 and LOVED Chocolate chip cookies!). We each write a message on the balloons to Jordan and release them. We tie a few balloons to his grave and eat the cookie cake. At Jacob's birthday party, we always include Jordan's name on the cake. (Posted by Hannah, 2009)

Although Jordan is deceased, his birthday celebrations continue through birthday traditions, like balloons and cake. Other participants in our research largely acknowledged enacting gift giving rituals for an individual's birthday; however, most staggering about Hannah's ritualized gift giving experience is the active inclusion of her deceased twin's presence in her living twin's birthday celebrations. Undoubtedly, for Hannah, ritualized occasions such as holidays, are immensely bittersweet celebrating the joy of her son Jacob's ongoing lived experiences while mourning her son Jordan's loss. As twins, the boys are uniquely connected. Even at 5-years-old, Jacob is actively participating in gift giving rituals with his deceased brother - sharing a cake, sending him balloons, and celebrating their shared birthday.

Hannah's experience demonstrates the emotional challenges bereaved consumers face when navigating ritualized contexts (Gentry, Kennedy, Paul, and Hill 1995b). Acknowledging a deceased family member through ritualized consumption practices (e.g., candles, cake, balloons, gifts) allows the surviving family members to include their deceased loved ones in ritualized occasions. Furthermore, the data suggest that individuals create new ritualized occasions in remembrance of their 
deceased loved ones. In particular, the anniversary of the deceased's death becomes a new ritualized occasion in which gifts play a central role. Some view this anniversary as a day of celebration and remembrance, while for others it brings anxiety and sorrow. As Eleanor discusses, she dreaded the first anniversary of her husband's death and chose not to acknowledge it as a ritualized occasion.

I was more done in by the anticipation and was glad when the day passed. I knew there would be no miracle feelings of it getting easier. I just wanted the day behind me because so much significance has been attached to it. It's not a date I plan to keep on my calendar. I'll never forget it anyway. When Steve's mother died, he remembered her on her birthday. He said, "Why would I want to do anything on the day I lost her?" It made perfect sense. She loved cardinals, so we bought little things as we found them. As the next year progresses, as I did last year, I want to do things that keep this house, our house. Not like a shrine, but I never want him erased from our home. And on his birthday I will celebrate he came into this world so we could find each other. That is the date that made all the difference in my life. (Posted by Eleanor, 2015)

Eleanor prefers to avoid commemorating the day her husband died, just as he avoided the day his mother died.

In contrast, Henry, whose wife died suddenly from an aggressive form of cancer, not only marks the yearly anniversary of his wife's death. He acknowledges each month that passes without her. He plans gifts in advance to mark each occasion.

I went to the cemetery yesterday. I placed a decoration I had built for the 38-month anniversary of Jane's death on her grave. I will write a poem for her, and a card, and buy some flowers to put up there Friday for Valentine's Day. But there will be no reciprocal gift or card here that day. I will wake up alone and go to bed alone and feel just as empty and alone as I did on Christmas Day-or any of the other holidays I have faced without her these 38 months. (Posted by Henry, 2014)

As Henry indicates, gift giving to his deceased wife at a cemetery is fundamentally different from the gift giving exchange between the couple, while she was alive. Henry has no expectations of reciprocity and recognizes that, tangibly, he will not receive a response from her. This lack of reciprocity in the gift giving exchange to the deceased can motivate some consumers to redirect the receiver of such gifts.

For example, Marjorie, whose daughter died as a teenager, continues to celebrate her daughter's birthday but gives 'birthday gifts' to herself and her other children.

My daughter Mary passed away 20 days before her 18th birthday. Her birthday was quite hard on us, and especially hard on me as her mother. This is the way I look at her birthday. It is still a reason for celebration. She was with us for almost 18 glorious years. It is a reason to celebrate and remember the time we had with her. April 8th will always 
be her birthday and nothing will change that. Every year for her birthday and anniversary of her death I plan to buy a charm for bracelets I'm starting for myself and her younger sisters. This year on Christmas I plan to get a new ornament for Mary to put on our tree for her. There is no right or wrong way to grieve. There is no right or wrong way to remember someone you love after they are gone. Light a candle, have some birthday cake, do balloons, fix favorite foods of the loved one. (Posted by Marjorie, 2010)

For Marjorie, the ritualized gift-giving occasions that were important while her daughter was living continue to be important after her death; however, the context has changed. She chooses to physically give material gifts to herself or her living daughters, as a proxy for giving to her deceased daughter. This example illustrates how gifting in honor of the deceased can share elements related to monadic gifting. Here, self-gifting can provide therapeutic benefits (Mick 1996) that help with the bereavement process. The family celebrates Mary's birthday and celebrates Christmas by performing traditional holiday gift giving but enacting it in a new way. In this way, the context of ritualized occasions guides the nature of the material gifts given to the deceased. The practice of gift giving to the deceased is embedded in the formality, tradition, and sentiment of each ritualized occasion.

\section{Temporal Delimiters}

Underscoring the practice of gift giving to the deceased are temporal delimiters. Time is fundamental to the grieving process (Bowlby 2012). While scholars increasingly reject the notion that grief follows a consistent pattern of time, there is a general consensus that bereavement is a longitudinal process (Davis, NolenHoeksema, and Larson 1998; Vezina, Bourque, Belanger 1988). Likewise, gift giving practices are influenced by temporal factors such as the passing of time and the time of year (Lowrey, Otnes and Ruth 2004; Ruth, Otnes, and Brunel 1999). The presence and practice of gift giving to the deceased are influenced by three temporal factors: time elapsed since death, the recipient's chronological age at the time of death, and the giver's motivation to establish experiential continuity as his or her life progresses.

\section{Time Elapsed}

The practice of gift giving to the deceased appears to decrease over time, following a loved one's death. As time passes, the surviving relatives and friends find it less critical to continue their gift giving rituals. Our research suggests that connective and characteristic gifts tend to be chosen during early stages of the grieving process as gift givers are driven to keep specific attributes and memories of the deceased alive and reinforce their connection with their loved ones. As time 
passes, these gifts may be replaced with more symbolic or decorative ones. Naturally, not everyone follows this progression.

On [my husband] Tim's grave we put five little statues... One is a Santa (that one is Tim) and then four little snowmen (those are me and the kids). We also put up a bent metal cardinal with a red glass eye and a couple of metal dragonflies with wings that move. One of Tim's siblings brought out a flag once too. I think that I would like to put a bird feeder of some sort out there, Tim liked birds, but we don't go there too much anymore. We just don't seem to need to. (Posted by Samantha, 2007)

As Samantha points out, she does not seem to need to decorate her husband's grave as she once did, suggesting that gift giving to the deceased may be more critical to the coping process immediately after a death.

Our data suggest bereaved consumers' visits to the cemetery and gift giving practices decline over time. What was once compulsory becomes optional. In terms of the obligation of reciprocity in gifting, bereaved consumers feel more compelled to give the deceased gifts, immediately following the loss of a loved one. In return, the practice helps them cope with the loss. In examining the ethnographic photographs over the course of seven years, the gravesites with the greatest presence of trinkets, decorations, and gifts were those who had most recently been laid to rest. Unique to the context of gift giving to the deceased is the act of disposing of the gifts. Unlike traditional dyadic gifting, in which a gift is given to a recipient, who can then choose to keep or dispose of the gift, gift giving to the deceased requires the bereaved gifter to not only provide the gift, but also dispose of it. As time passes, bereaved gifters are faced with the choice of when to remove gifts and what to do with them.

...I feel like I need to put a video camera out there to make sure nothing is amiss. Especially when you have a reputation of a really well attended gravesite, the horror of people visiting when I'm not there and seeing it empty gives me a sinking feeling in my stomach. Sometimes I tell my husband to just swing by after work and make sure everything looks okay, even though it's 40 mins out of his way. We bring home the stuff that's too weathered and sometimes fix it up to take it back out, like if it's a holiday gift. I keep some of her old cemetery stuff in my closet, unless it's broken or just really old. I never go back and think about the old flowers or things we've removed. It doesn't really matter how long [a gift] was there... it's about the moment I remember when I was placing it there. (Posted by Julia, undated)

Julia also takes care to make sure she attends to her daughter's grave in a timely manner. She does not want too much time to pass before performing maintenance on the grave's appearance, demonstrating the responsibility living relatives and friends have in caring for their deceased loved ones, even long after death. As time passes, Julia must decide what to do with these gifts. Some items become keepsakes, placed 
in boxes on shelves, just as consumers do with childhood keepsakes. Some items are discarded due to wear and tear. Although the deceased never physically touched these material objects while they were living, grave gifts become imbued with identity and representative of their disembodied selves. Objects left behind after death are fundamentally connected to the memory of the person who owned them (Turley and O'Donohoe 2012). In contrast, restorative giving is experiential and intended to create new memories in the mind of the giver. Previous research suggests material goods at the end-of-life are distributed to others, often in the immediate family (Bradford 2009; Price, Arnould, and Curasi 2000); material gifts left at the graveside become the responsibility of the primary caretaker of the grave, as time passes. As we will discuss in the next section, the responsibility the living feel to take care of their loved one's grave over time is directly tied to the chronological age at which an individual died. No matter how much time has elapsed, young children appear to have a high prevalence of material goods on their gravesites.

\section{Chronological Age}

The death of a child can be especially traumatic (Rubin 1993). In gift giving to the deceased, young children tend to show the greatest prevalence of gifts at their gravesites. The types of gifts given are often determined by the age at which someone died. Figure 4 shows two images of the headstone of a ten-year-old boy who died in 1996 - the first image taken in 2008 and the second image taken in 2015.

Insert Figure 4 here

Nearly two decades passed since the young boy's death; however, his grave prominently displays gifts that reflect the personality and characteristics of a young boy of 10. This demonstrates how elapsed time, discussed in the previous section, becomes less important in the case of children. Parents feel particularly compelled to care for their deceased children's graves by bringing gifts. Despite the seven-year time lapse between our photographs in Figure 4, the young boy has an abundance of Christmas decorations and gifts on his gravesite. Interestingly, the toys left at his gravesite continue to reflect the age at which the young boy died. That is, the deceased tend to stay frozen in time at the age of death; however, some survivors mark missed milestones (e.g., "Sweet 16," graduation) with gifts. For instance, Antonia, who lost her child as an infant, purchased a balloon to take to the cemetery for his birthday. 
I bought a balloon for his birthday. Of course it didn't last very long. But it was something a 2 yr old would have liked on his birthday. And it was a visible reminder to others that a child was lost. (Posted by Antonia, 2010)

Antonia's statement demonstrates the struggle bereaved parents face when gifting to their deceased children. When children die, their future selves die with them. Parents, like Antonia, experience important milestones without their children and struggle to remember them as they were while acknowledging the individuals they could have been. Antonia notes the balloon is something a two-year-old would have liked, not necessarily something her son liked because he died as an infant. Restorative gifts present a paradox in terms of chronological age - the deceased remain frozen in time at the age they were, but their left ones are continually reminded of milestones (e.g., birthdays, graduations) they would have experienced if they were still living. Possible selves describe "an individual's ideas of what they might become, what they would like to become, and what they are afraid of becoming" (Markus and Nurius 1986, p. 954). Similarly, grave gifts can reflect who a deceased loved one might have become. While gift giving to the deceased is not exclusive to young children, the prominence of the ritual and its persistence over time appear to be tied to the age at which an individual dies. Gravesites for children and younger individuals tend to include characteristic and customary gifts; gravesites in which older individuals were buried err on the side of traditional flowers as decoration, if at all.

\section{Experiential Continuity}

A particularly interesting motive for gift giving to the deceased is a desire for continuity. Survivors aim to include their deceased loved ones in their lives through gift giving. The deceased individual cannot be physically present at momentous events (e.g., vacations, graduations, weddings). Instead, family and friends make efforts to keep their loved ones "in the loop," in a sense, by symbolically bringing those events to the gravesite. For instance, in the following quote, Ellen discusses how she has used gift giving to include her deceased younger sister in her personal life events.

My little sister passed away 13 years ago. We decorate her grave with all sorts of things. When I go on vacation, I pick up something for her grave - sand from a beach, rocks from a mountain, a shot glass from Las Vegas, etc. She planted an apple tree a few years before she died, but never got to see it bear fruit. When it got its first apple, my mom took it to her grave. One Christmas we left the wishbone from the turkey at her grave because she always fought over the wishbone. When I finally graduated from college (after attending night school forever), I left the tassel from my graduation at her grave. We leave pictures, letters, statues, cards, and just about anything you can think of. I think everyone deals with death differently. For my family, we deal with her death by 
including her in things we continue to do. She is gone from this earth, but not from our hearts and our memories. Visiting my sister's grave and leaving trinkets is our way of keeping her with us - even if only in our hearts and memories. For some this may not seem necessary. As I said, we all deal with it differently. (Posted by Ellen, 2007)

The gifts Ellen brings to decorate her sister's grave do not reflect the characteristics or life experiences of the deceased. Rather, they reflect the moments of which Ellen's sister has been absent. Ellen uses material items to symbolically share her world with that of her deceased sister's. Ellen's sister continues to be a part of their shared family identity (e.g., Epp and Price 2008) and experiences, despite physically being gone. As Ellen suggests, this allows her family to include her sister in their evolving life. Thus, her view of death is not one of stagnation and time permanence. The data suggest that this perspective is common among individuals who partake in gift giving to the deceased.

[My dear husband] and I have a [birthday] party for my daughter every year, complete with cake and candles, and a present appropriate to the age she would be (which we later donate to a local charity). It's just the two of us at the moment, but our future children will be involved in the day, and it helps us to feel like she's there with us again. This year, because we were pressed for time due to our move, we got lunch at Burger King (my daughter's favorite) and got an "extra" kid's meal for her...she'd be seven now. But there are no rules about what you should do. Do whatever makes you feel like you have honored your child and commemorated the day without putting yourself out of your comfort zone. (Posted by Liza, 2009)

Like Ellen, Liza's view of life after death is dynamic. She and her husband purchase a gift that is appropriate for the age their daughter would be, not the age she was. In Liza's mind, her daughter does not stay the age that she was at death. Thus, her birthday is celebrated as such. Gift giving provides a way for the living to include the deceased in a continual and evolving manner. Gifts serve as symbolic proxies of the life experiences and occasions for which their loved ones cannot be physically present.

I don't live near where my mom is buried, so I just buy some of her favorite flowers to keep in my kitchen so I can smile when I see them. (Posted by Meghan, undated)

This will be our first Mother's Day without Gran (whose birthday is just a week after), and since we don't live near where she's buried, we can't visit the cemetery with the rest of the family. We will just celebrate with her favorite yellow cake with chocolate frosting (Posted by Danielle, undated) 
Even when geographical distance inhibits a mourner's ability to visit the grave itself, gifting to the deceased is still symbolically enacted. Many narratives in our research reflect strategies for experiential continuity.

\section{Social Factors}

Cemeteries are public spaces, and as our data reveal, in many ways, gift giving to deceased loved ones at cemeteries is a public performance. Historically, a variety of factors influence burial decisions, such as religious affiliation, shared family gravesites, and socioeconomic status (Kephart 1950). While undoubtedly an important decision that must be made following the death of a loved one, our study does not include the investigation of how consumers choose gravesites; rather, we are concerned with cemeteries as a context in which material rituals are performed. Gifts, trinkets, and décor left on each grave signal to others that the person buried there is cared for by living relatives and friends. The cemetery acts as a neighborhood, with its own standards and social expectations. Moreover, consumers view cemeteries as a place to be in community with deceased loved ones, and many gifts left at the cemetery are socially consumed. Thus, findings from the data suggest gift giving to the deceased is influenced by three social factors: social comparison relative to other gravesites, a collective responsibility to take care of others' gravesites, and the social exchange of gifts expressly intended for symbolic consumption in the afterlife.

\section{Social Comparison}

Although it may seem trivial to "keep up with the Joneses" in a cemetery, the data reveal, to some extent, surviving friends and relatives make efforts to signal their loved one's social identity by adjusting their gift giving rituals to the standards presented on neighboring graves. In this way, gifts are not only meant for the deceased, but also for the living who visit them. Our data suggests that gifts driven by social comparison tend to fall into the decorative, symbolic, or customary categories. Such gifts are less personal as they do not aim to reflect information about the deceased, like characteristic and connective gifts, instead, they serve a primarily aesthetic role.

\footnotetext{
When I go to [my husband] Tim's grave I like to take the time to drive around and look at the other grave's decorations. There is one not too far from John that has all kinds of things on there; wind chimes, statues, necklaces, toys, a plaque on the tree next to it, a bird feeder on the tree, etc. There are ones that get Christmas decorations each year... even one that has a Christmas tree on it and the family lays it down and then tacks it into the ground so it won't blow away. In the graveyard where John is, we are limited to the size and style of gravestone. It can only be the kind that lies flat... and I assumed that it is for ease of mowing, but they still have to mow over all the memorial trinkets that are left behind. (Posted by Samantha, 2007)
} 
Samantha has not only noted the types of decorations that other graves display at a different graveyard, but how they have been implemented for display. It appears as though she wants to display similar types of items, but recognizes that she is restricted by limitations at this graveyard for maintenance purposes. At a different cemetery, a grieving mother does not appear to have faced some of these restrictions, and is concerned with keeping her son's grave as beautiful as those around him.

\begin{abstract}
A really good friend of mine lost his 18 day old baby boy back in November. I've taken it really hard and I think about little Jacob daily. I went to visit him a few weeks after he was laid to rest and took him a teddy bear that kneels and when you push his tummy he says a prayer. I visited him again at Christmas and took a little baby angel figurine to put on his grave. I hadn't been back to visit him since, but I stopped this morning after dropping the kids off at school. I felt so sad. All the other babies that are buried by him have such beautiful grave sites with flowers and stuffed animals, and all baby Jacob has is a marker and the teddy bear and angel I took. Now that spring is here and the weather is so beautiful I'd really like to plant some flowers at his grave and make it beautiful, just like he was. I'm thinking about going to get some and planting them this afternoon before I pick the kids up. ... I know this probably seems stupid. It just makes me sad to see his grave so bare when all the others around him are decorated so beautifully. (Posted by Roberta, 2010)
\end{abstract}

As the two previous examples suggest, gravesite visitors are cognizant of the décor on their loved ones' neighboring graves and alter their gift giving practices as a result. Moreover, the theme of conformity is supported by evidence from Phase 1 of our study in that graves with many gifts and adornments tended to be located in a central region or patches of space within each cemetery. In many ways, in the realm of gift giving to the deceased, the décor on and around headstones is a tangible representation of the extent to which surviving friends and relatives care about their deceased loved one. Thus, individuals make efforts to keep up the appearances of their loved ones' graves in order to conform to the standards of the surrounding headstones. This echoes the common funerary practice in Ghana where valuable objects and lavish celebrations are used to posthumously construct identities in accord with the desired the social status of the deceased (Bonsu and Belk 2003).

Furthermore, the netnography revealed the desire of gift givers to be considerate of their loved ones' "neighbors" when choosing the type and number of gifts to leave at the grave. Akin the desire to keep the neighborhood clean and aesthetically pleasing, some gift givers express their distaste for cheap trinkets, such as plastic toys, or weathered items, which they feel degrade the quality of the neighborhood. 
... However I do feel there needs to be limits about how much can be left at a grave site. When the point comes that you need wire baskets stuck in the ground next to the grave to hold all the stuff, that is too much. A windchime is fine, even a solar light is ok (maybe the family can't afford one of the actual eternal lights you see next to graves some times) even a stuffed animal is ok as long as it is taken away before it gets all rain soaked and matted and gross, but everything in moderation. Although people do pay for their cemetery plot the cemetery as a whole is a shared space and people need to be considerate of their neighbors. (Posted by Carrie, 2007)

Carrie acknowledges the shared nature of the cemetery space and analogizes the cemetery as a neighborhood, with a set of unwritten community standards for cemetery gift giving and décor. Carrie even mentions a level of social status and socioeconomic influences at play in cemetery décor, noting that a solar light is acceptable for those who may not be able to afford the preferred eternal light. In line with this concept of the cemetery as a neighborhood, a family's desire to "keep up with the Joneses" can negatively impact neighboring families, especially when cemetery rules are broken. Akin to the neglected upkeep of a home or when one does not adhere to homeowners' association rules, neighbors may become soured.

\footnotetext{
Everyone is given 15" in front of the headstone and the rest of the grave is grass so that the mowers can run up and down the rows keeping everyone's grave neat. That can't happen when somebody decides to erect a picket fence 6ft long filled with coloured stone chippings. There's definitely a "keeping up with the Jones'" attitude about graveside mementos. One has a bunch of flowers, the next wants a bunch of flowers and a balloon, the next one wants a bunch of flowers, two balloons and a windchime and so it goes on. Everyone thinks that they should be the exception to cemetery rules. (Posted by Greg, 2008)
}

Greg acknowledges the social comparison that takes place at cemeteries. Survivors compare their loved ones' gravesites to others, and some get caught up in the mission to outdo one another. This can be to the detriment of the overall cemetery maintenance and, as Greg mentions, individual consumers tend to act 'above the law' by breaking cemetery rules.

\section{Collective Responsibility}

Continuing to view the cemetery as a neighborhood, both the photographic and netnographic data revealed evidence of feeling the responsibility to take care of their "cemetery neighbors." These neighborly actions manifest in the form of maintaining the plots of others near their loved ones, caring for extended family members' gravesites, and even gifting to strangers. Gifts driven by collective responsibility tend to be symbolic, decorative, or customary. Maintenance of other 
graves appears to be common through picking up fallen gifts, removing dead flowers, and watering.

\begin{abstract}
I went to the cemetery yesterday morning. I go there every Saturday, usually in the morning. Jane and I went there most Saturday mornings when she was alive. We went to her mother's grave. Her mother always liked to hear people talking, so we would talk there. It was always quiet. We would water the flowers we took there. We would water the flowers on other nearby graves if they looked dry, pick up the vases and pots that had fallen over in the wind. (Posted by Henry, 2015)
\end{abstract}

Within a single cemetery, the survivors of the loved ones buried there share an unofficial responsibility to look out for and care for the maintenance of surrounding graves. Such shared intracommunity gifting activities support Weinberger and Wallendorf's (2012) discussion of gifts in the context of a moral economy. One potential cause for the sense of collective responsibility may be bereaved consumers' attachment to the cemetery as a physical space. Debenedetti, Oppewal, and Arsel (2014) find consumers develop emotional place attachment through experiences of homeyness and familiarity. In turn, they are more likely to volunteer and overreciprocate in gift giving. For bereaved consumers, the cemetery becomes a physical home for their deceased loved ones. Many of the informants in our study use language signaling emotional attachment to the cemeteries where their loved ones were buried (e.g., "visiting my brother," "going to see my mom"). Thus, those who engage in gift giving to their deceased loved ones feel emotionally attached to the physical location of the cemetery and are motivated to care for their neighbors. Gift givers feel a responsibility to take care of family members, as noted by Gigi who feels the need to provide the care for members of her extended family. She discusses her dedication to up keeping not only her father's plot, but decorating those of her other relatives.

Buying flowers for the cemetery is going to bankrupt me, because I have too many dead relatives now, so I will have to stop going so often at some point. (Posted by Gigi, 2015)

Bereaved consumers, like Gigi, can feel overwhelmed by the upkeep of cemetery gift giving and grave maintenance. The collective responsibility to care for extended family's graves, as Gigi notes, can become extremely prohibitive in terms of costs. In the context of ritual gift giving, Gigi suggests the cost will be the demise of her actions. She anticipates ending her cemetery visits altogether, rather than merely going to the cemetery without flowers. To Gigi, the idea of visiting her deceased relatives' graves without a gift to present is worse than not going at all. 
A last emergent theme in this study was that of socially exchanged gifts, specifically sent to deceased loved ones or expressly intended for consumption in the afterlife. Overall, bereaved consumers express an awareness that their restorative giving practices are coping mechanisms for themselves, and they cannot expect to get a gift in return. Yet, the data reveal that some survivors share the common belief that their deceased loved ones can receive and consume gifts in the afterlife, and in turn, their loved ones send them "signs." Balloons appear to be the most common gift to be "sent" to the deceased.

This year we had a birthday cake that said "Happy 18th birthday Mary and we let off balloons at the park in honor of her at dusk. There was only one star out, my daughters commented on that and I looked at them, smiled and said of course, don't you know that is your sister opening the door into heaven so she can get her balloons. I won't lie. It was hard on me to put up a smile and say that but I think it really helped them and myself since I could see her doing something like that. We as a family have decided that every year on her birthday we will do something since it is our way to honor her.

(Posted by Marjorie, 2010)

Often accompanied by individual religious leanings, there appears to be a belief in some sort of reciprocity in the form of 'signs' from loved ones after death. Still, these signs are interpreted in the mind of the bereaved consumer. Marjorie's interpretation of the star in the sky as a door to Heaven is embedded in her personal religious beliefs and her need for perceived reciprocity. The same star viewed by someone else would not carry the same meaning. Pennies are the most common tangible 'signs' by deceased loved ones. Respondents shared stories about "pennies from Heaven" which are thought to be sent from deceased loved ones.

Our very much beloved nephew Josh passed away at age 39 with leukemia. The day he died, his 4 year old son found a shiny new penny. Every time any of us visit Josh's grave we put pennies on his slab and headstone - Anytime any of us find a penny anywhere we think of him..... (Posted by John, 2007)

These gifts represent a perceived, active social exchange between the survivor and the deceased. Other respondents mentioned items that were placed inside their loved ones' caskets prior to their burials, including but not limited to, cash, medals, alcohol bottles, athletic memorabilia, stuffed animals, letters, books, and pictures. The respondents suggested that their loved ones could take these buried items with them for use in the afterlife. However, items such as these are not limited to being buried with the deceased. Survivors continue to enact the social exchange through leaving similar items at the cemetery, such as the empty mini bottles of Jack Daniels Whiskey shown in Figure 5 . These bottles are presumably either consumed by the gifter at the 
cemetery or symbolically poured out over the grave. Gifts in this category tend to be characteristic and connective.

Insert Figure 5 here

\section{DISCUSSION AND FUTURE DIRECTIONS}

Grief is a complicated, dynamic process, and no two experiences are exactly alike (Stroebe and Schut 1999). Bereavement results both from the death of a loved one and from the death of the traditions, experiences, and practices once shared with that loved one. In line with Lowrey, Otnes, and Ruth (2004), surviving consumers not only grieve the physical loss of their loved ones, but they also grieve the loss of the gift giving oriented rituals they once shared. Thus, gift giving to the deceased is not just about coping with death; it is about grieving the loss of the birthdays, the anniversaries, the holidays, and the daily practices that the deceased loved one can no longer physically experience. To that end, our study suggests bereaved consumers are not willing to readily abandon gift giving rituals they shared with deceased loved ones. In fact, they actively resist relinquishing shared gift giving rituals. Instead, they practice restorative giving to personally cope with their loss and to continue the relationship they shared with the deceased. Our framework (see Figure 3) illustrates how restorative giving practices are guided by materiality and identity, embedded in ritualized occasions (e.g., birthdays, holidays, vacations, "just because"), and influenced by temporal and social factors.

Our research reveals that objects left at gravesites are not necessarily material goods that were touched by the deceased loved one; rather they are often contemporary gifts of the present. They are letters written in the present day, trinkets purchased on current vacations, and annual offerings for each passing birthday. In line with previous research on materiality and consumption rituals (e.g., Chitakunye and Maclaran 2014), materiality in gift giving to the deceased provides the living with a tangible way to cope with their loss and enables relationships with the deceased to continue. In this sense, gift giving to the deceased offers a restorative alternative to traditional grief work centered on "letting go" and "moving on" through offering the possibility of keeping the relationship with the deceased alive. Restorative giving provides a level of tangibility to the intangible bereavement experience. Deceased consumers receive material gifts and goods, gaining ownership of these products left at their gravesites. In turn, the survivors continue active relationships with deceased loved ones and gain comfort through their ritualized restorative giving practices. 


\section{Restorative Giving versus Existing Gift Paradigms}

Restorative giving provides a new perspective of gift giving practices, distinct from previous theoretical perspectives (e.g., social exchange, monadic exchange, agapic giving, monadic giving). We find support for some elements of established gift exchange theories; however, restorative giving is unique. A primary contribution of this research lies in challenging the traditional notion of reciprocity in our theoretical understanding of gift giving (Mauss 1954). Exploring gift giving to the deceased reveals the dynamic nature of reciprocity in gift giving practices. Within the field of marketing, the literature on gift giving rituals is well-established, with the obligation of reciprocity viewed as central to the practice (Belk 1976; Sherry 1983). However, death brings the dissolution of one side of the gift giving dyad. When a loved one dies, the reciprocity loop dies as well. Surviving loved ones use material goods to redefine the reciprocity loop, post-mortem. The surviving gifter either redirects the reciprocity (e.g., gifts to others in memory of the deceased), reestablishes reciprocity (e.g., gifts left at a gravesite for consumption in the afterlife or in hopes that someone will do the same for them), or rejects the entire notion of reciprocity (e.g., stops giving gifts or continues to merely enact the script of gift giving).

In terms of reciprocity, one could argue restorative giving follows a therapeutic self-gifting model (e.g., the giver is receiving comfort in the gifting process; Mick and DeMoss 1990). A key difference between therapeutic self-gifting and restorative giving lies in the intended recipient of the material gift. Restorative giving is behaviorally other-oriented (e.g., dyadic) but emotionally self-oriented (e.g., monadic). Our research establishes that bereaved consumers take gifts to the cemetery to "give" to their loved ones in a more dyadic way. Monadic gifts are conceptualized as "selfindulgence to remedy negative behavioral or psychological states, typically based on physical illness or a feeling of non-success in some aspect of life" (Mick and DeMoss 1990). This perspective presents a materialistic view of self-gifting (Belk 2001; Park 2015). In contrast, bereaved consumers do not treat themselves to material gifts to remedy their loss. Respondents in our study exhibit some therapeutic tendencies of self-gifting; however, behaviorally, their gifting practices are other-oriented.

Restorative giving is somewhat paradoxical in that bereaved consumers tangibly give to someone else (e.g., a deceased loved one) with the awareness that the gifting practice is emotionally beneficial to themselves (e.g., provides adaptive coping). Restorative gifts are explicitly "given" to the deceased versus traditional self-gifts, which are both purchased and consumed by the gifter. In other words, our respondents give gifts to their deceased loved ones; yet, in the end, the gift benefits themselves the most. 
Restorative giving acts to maintain a sense of normalcy or repair a broken reciprocity loop. In this way, the practice is relational and reflects elements of social exchange (Belk 1976; Sherry 1983; Lowrey, Otnes, and Ruth 2004). The primary goal of social exchange is the maintenance of reciprocal relationships (Sherry 1983). Indeed, a key motive for restorative giving is maintaining or extending a relationship with the deceased; however, the relationship is not reciprocal in the traditional Maussian sense. Bereaved consumers do not expect their deceased loved ones to tangibly or equally reciprocate. A letter "sent" on a balloon to a deceased loved one will not warrant a reciprocal response. A gift left at a grave for a seasonal holiday will not secure a tangible gift in return. Some bereaved consumers seek "signs" of reciprocal social exchange from their deceased loved - such as seeing a star in the sky or finding a lucky penny. Bereaved consumers assign meaning to these tangible or intangible things. They want to believe restorative giving is an interactive practice, despite the impossibility of receiving a tangible gift from a deceased loved one.

In line with Klein, Lowrey, and Otnes (2015), restorative giving is grounded in identity-based motivations, which place less emphasis on reciprocity and more emphasis on identity-maintenance. Restorative giving is an identity-laden process. Gifts presented to deceased loved ones not only reflect the recipient's identity (e.g., a Hot Wheels car given to a child) they also characterize the nature of the relationship shared between the giver and recipient (e.g., a father gives his deceased son a Hot Wheels car because they often played with them together). Importantly, while gifts may be connected to identities and memories of the deceased, restorative giving involves the creation of a new experience.

As we demonstrate in our findings, restorative giving is bound by social factors, including social comparison relative to other gravesites and a collective responsibility to take care of others' gravesites. This supports previous gifting research by demonstrating third-party influences on giving over time (Lowrey, Otnes, and Ruth 2004); however, unique to our study, the dyad is between a deceased and a living consumer. Bereaved consumers seek to 'keep up appearances' at their loved ones' gravesites. Through restorative giving, they sustain relationships with their deceased loved ones and signal to the public how important their loved one continues to be.

Given the emotional and sacred relationship shared between the living and the deceased, we might expect restorative giving to follow an agapic model (Belk and Coon 1993). Somewhat surprisingly, restorative giving is more accurately motivated by a personal need for comfort and coping, not inherently selfless love. Bereaved consumers also express a clear obligation and responsibility to give to deceased loved ones. Agapic giving does provide some understanding with regard to reciprocity. That is, restorative giving, like agapic giving, is communicative but does not demand tangible reciprocity. Reciprocity in gift giving to the deceased is variable, defined by 
each consumer as he or she traverses the coping process. Bereavement does not take place in isolation; it is both an intra- and interpersonal process (Stroebe and Schut 1999).

As Camerer (1988) suggests, gifts spur investments in future reciprocal relationships. In our study, the future relationship between giver (e.g., living consumer) and receiver (e.g., deceased) is disrupted; yet the givers continue to give. Through restorative giving, bereaved consumers continue to invest in relationships with their deceased loved ones. Critical factors in understanding death in consumer culture lie in the ongoing interpersonal relationship between survivors and their deceased loved ones and how identity is constructed through material objects after death. In a narrow view, grief is seen as something that must be overcome or cured. However, when we consider grief as a process, we begin to recognize the liquidity of it (Klass, Silverman, and Nickman 1996). Restorative giving serves to navigate the tenuous emotions that accompany bereavement, particularly as consumers seek to establish normalcy through restorative giving practices.

\section{Contributions to Our Understanding of Death and Consumption}

Our research directly contributes to advancing the discussion on person-object relationships after death (Turley and O'Donohoe 2012) by uniquely examining the role of new material things in the bereavement process. Previous research explores specific and finite moments related to the loss of a loved one, such as how consumers dispose of or memorialize products at the end of their lives (Bradford 2009; Price, Arnould, and Curasi 2000; Cherrier and Murray 2007; Lastovicka and Fernandez 2005; Turley and O'Donohoe 2012) and the important role of material goods in funerary customs (Bonsu and Belk 2003). In contrast, our research uncovers practices by which deceased consumers continue to amass material goods, as noted by our longitudinal photographic observations. We argue that the deceased continue to be consumers, as they are recipients of gifts or catalysts for consumption. Restorative giving moves beyond funeral rituals (Bonsu and Belk 2003) and examines how living consumers continue to interact and engage with their deceased loved ones through the purchase and deposition of new material goods. These material objects reflect elements of the deceased's identity, the bereaved consumer's identity, and the relationship they continue to share symbolically. Thus, restorative giving is used as a mechanism of identity construction, maintenance, and development, on a spectrum from personal relational identity to broad cultural identity. Previous research suggests items owned by deceased loved ones become sacred (Gentry, Kennedy, Paul, and Hill 1995a). Our study builds on this work by demonstrating the significant role of new material goods in the grieving process and the new memories created through their consumption. 
Future research on death and consumption should further articulate the role of deceased loved ones in shaping family identity and consumption activities.

By recognizing the deeper meanings and motives underlying the ritual of gift giving to the deceased, this study emphasizes the role of consumption in the grieving process. We primarily focus on gravesites with headstones or tangible markers; however, some evidence suggests gift giving to the deceased persists in alternatives like cremation in which no physical site exists. Further exploration of gift giving practices of this group may provide insights into this phenomenon. Similarly, individuals who choose not to partake in such gift giving rituals did not have the opportunity to respond. Thus, future research could investigate reasons why some people reject the ritual of gift giving to the deceased, or why some people terminate their gift giving practices over time.

Future research should seek to understand how other contexts, such as charitable giving or digital gifts, might reflect a restorative perspective of giving. For instance, as Belk (2013) notes, consumers now create online memorials, which provide a sort of virtual gravesite for mourners to pay their respects and share memories. Previous research suggests online memorials help living consumers maintain relationships with the deceased; however, virtual communication between the living and the dead may stunt the grieving process (Mitchell, Stephenson, Cadell, and MacDonald 2012). 'Digital shrines' are purposeful and lack the "various means available to physically circumscribe the pictures, flowers, candles and inscriptions that make up a spontaneous shrine" (Paton and Figeac 2015, p. 28). As consumers increasingly mediated their grief through technology, future research should explore the 'digitization' of cemeteries and the blurred boundary between restorative material gifts and the virtual landscape (e.g., posting digital photos of physical gravesites).

A deeper investigation into the temporal delimiter of chronological age may yield a richer understanding of these gift giving practices. Future research may investigate how gift givers choose whether to leave gifts that reflect a loved one who continues to grow and "age" as a member of the community as, or if they choose gifts that are reflective of the deceased age at the time of their death, ultimately keeping the deceased "frozen" in time. From an interpersonal perspective, gravesites can become socially contested places, as some informants mentioned contentious experiences with other living family members at the gravesite (e.g., leaving "ugly" objects, failure to care for the grave, throwing away or removing objects without permission, running into an ex-spouse at the gravesite when leaving a gift). While this was not central to our current research, understanding the interpersonal relationships between bereaved consumers may advance theoretical understandings of gifting practices. 
Given the limitations of the netnographic and observational data, this research cannot fully explore this phenomenon. Interesting areas for further research include investigating the processes in which gift givers choose gifts for the deceased and how they define what types of objects are appropriate gifts. Additionally, another interesting avenue would be to explore situations surrounding the removal of gifts. For instance, how do gift givers decide when to remove gifts and what to do with the gift after removal? If the gift is removed by a third party, such as a groundskeeper, what happens to the essence of the gift and how does this act affect the gift giver? Lastly, we know little about how family roles play into this phenomenon. An exploration of how family roles affect the gift giving process and expectations around it is warranted.

Finally, we recognize bereavement as a culture-bound process. While our data represent a variety of geographic areas across the United States, we do not account for gift giving and bereavement practices across cultures. In order to gain a more complete understanding of gift giving to the deceased, future research should explore practices of gift giving to the deceased in non-Western cultures, considering societal values (e.g., collectivist vs. individualistic) and religious beliefs (e.g., Islam, Judaism, Buddhism, Agnosticism) unique to each culture. Our research primarily addresses the consumer perspective. Additional insights may be garnered by exploring cemeteries and grave gifts from a market systems perspective, addressing the role of cemetery policies, historical discourses, and funerary service providers in postmortem gift giving practices. Our study provides a foundation by which researchers can further understand the role of deceased consumers in prompting marketplace activity. Bereaved consumers cannot bring their loved ones back, but they can continue to interact with them symbolically. Through restorative giving, the deceased are physically gone but not tangibly forgotten. 


\section{References}

Andreasen, Alan R. 1984. "Life Status Changes and Changes in Consumer Preferences and Satisfaction." Journal of Consumer Research 11 (3): 784-794.

Belk, Russell W. 1976. "It's the Thought that Counts: A Signed Digraph Analysis of Gift-Giving." Journal of Consumer Research 3 (3): 155-162.

Belk, Russell W. 1979. "Gift Giving Behavior." In Research in Marketing, edited by Jagdish Sheth, 95-126. Greenwich, CT: JAI Press.

Belk, Russell W. 1988. "Possessions and the Extended Self." Journal of Consumer Research 15 (2): 139-168.

Belk, Russell W. 1992. "Moving Possessions: An Analysis Based on Personal Documents from the 1847-1869 Mormon Migration." Journal of Consumer Research 19 (3): 339-361.

Belk, Russell W., and G.S. Coon. 1993. "Gift Giving as Agapic Love: An Alternative to the Exchange Paradigm Based on Dating Experiences." Journal of Consumer Research 20 (3): 393-417.

Belk, Russell W. 1996. "The Perfect Gift." In Gift Giving: A Research Anthology, edited by Cele Otnes and Richard F. Beltramini, 59-84. Bowling Green, OH: Bowling Green State University Popular Press.

Belk, Russell W. 2010. "Sharing." Journal of Consumer Research 36 (5): 715-734.

Belk, Russell W. 2013. "Extended Self in a Digital World." Journal of Consumer Research 40 (3): 477-500.

Bonanno, George A., and Stacey Kaltman. 1999. "Toward an Integrative Prospective on Bereavement." Psychological Bulletin 125 (6): 760-776.

Bonsu, Samuel K., and Russell W. Belk. 2003. "Do Not Go Cheaply into That Good Night: Death-Ritual Consumption in Asante, Ghana." Journal of Consumer Research 30 (1): 41-55.

Borgerson, Janet L. 2005. "Materiality, Agency, and the Constitution of Consuming Subjects: Insights For Consumer Research." In NA - Advances in Consumer Research, edited by Geeta Menon and Akshay R. Rao, 32: 439-443. Duluth, MN: Association for Consumer Research.

Bowlby, John. 1980. Attachment and Loss: Vol. 3. Loss: Sadness and Depression. New York: Basic Books.

Bowlby, John. 2012. The Making and Breaking of Affectional Bonds. New York, NY: Routledge.

Bradford, Tonya Williams. 2009. "Intergenerationally Gifted Asset

Dispositions." Journal of Consumer Research 36 (1): 93-111. 
Cherrier, Hélène, and J. B. Murray. 2007. "Reflexive Dispossession and the Self: Constructing a Processual Theory of Identity." Consumption Markets \& Culture 10 (1): 1-29.

Chitakunye, Pepukayi, and Pauline Maclaran. 2014. "Materiality and Family Consumption: The Role of the Television in Changing Mealtime Rituals." Consumption Markets \& Culture, 17 (1): 50-70.

Creswell, John W. 1998. Qualitative Inquiry and Research Design. Thousand Oaks, CA: Sage.

Davis, Christopher G., Susan Nolen-Hoeksema, and Judith Larson. 1998. "Making Sense of Loss and Benefiting from the Experience: Two Construals of Meaning." Journal of Personality and Social Psychology 75 (2): 561-574.

Debenedetti, Alain, Harmen Oppewal, and Zeynep Arsel. 2014. "Place Attachment in Commercial Settings: A Gift Economy Perspective." Journal of Consumer Research 40 (5): 904-923.

Doss, Erika. 2008. The Emotional Life of Contemporary Public Memorials: Toward a Theory of Temporary Memorial. Amsterdam: Amsterdam University Press.

Durkheim, Emile. 2008. The Elementary Forms of the Religious Life [1915]. Translated and edited by Joseph Ward Swain. Mineola, NY: Dover Publications Inc.

Epp Amber M., and Linda L. Price. 2008. "Family Identity: A Framework of Identity Interplay in Consumption Practices." Journal of Consumer Research 35 (1): 50 70.

Forest Hill Cemetery: A Guide (2016), "Rituals", available at http://foresthill.williamcronon.net/rituals/, accessed 28 September 2016.

Francis, Doris, Leonie Kellaher, and Georgina Neophytou. 2005. The Secret Cemetery. Oxford and New York: Berg.

Gentry, James W., Patricia F. Kennedy, Catherine Paul, and Ron P. Hill. 1995a. "Family Transitions During Grief: Discontinuities in Household Consumption Patterns." Journal of Business Research 34 (1): 67-79.

Gentry, James W., Patricia F. Kennedy, Catherine Paul, and Ron P. Hill. 1995b. "The Vulnerability of Those Grieving the Death of a Loved One: Implications for Public Policy." Journal of Public Policy \& Marketing 14 (1):128-142.

Gibson, M. 2008. Objects of the Dead: Mourning and Memory in Everyday Life. Melbourne University Publishing.

Giesler, Margaret. 2006. "Consumer Gift Systems." Journal of Consumer Research 33 (2): 283-290.

Glaser, Barney G. and Anselm L. Strauss. 1967. The Discovery of Grounded Theory: Strategies for Qualitative Research. Chicago, IL: Aldine Publishing Company. 
Goffman, Erving. 2008. "The Presentation of Self in Everyday Life: Selections" [1959]. In Sociology: Exploring the Architecture of Everyday Life Readings, ed. David M. Newman and Jodi O'Brien, 120-129. Thousand Oaks, CA: Pine Forge Press.

Grainger, Roger. 1998. The Social Symbolism of Grief and Mourning. London: Jessica Kingsley.

Habegger, Becca. 2015. Grieving Mother Objects to Cemetery Policy. WBIR.com, http://www.wbir.com/news/grieving-mother-objects--cemetery-policy/1203692, accessed 28 September 2016.

Hallam, Elizabeth, and Jenny Hockey. 2001. Death, Memory and Material Culture. London, UK: Bloomsbury Academic.

Harper, Sheila. 2012. "I'm Glad She Has Her Glasses On. That Really Makes the Difference': Grave Goods in English and American Death Rituals." Journal of Material Culture, 17 (1): 43-59.

Hayslip, Bert, Jr., and Cynthia A. Peveto. 2005. Cultural Changes in Attitudes Toward Death, Dying, and Bereavement. New York, NY: Springer Publishing Company. Hockey, Jenny, and Janet Draper, 2005. "Beyond the Womb and the Tomb: Identity, (Dis)embodiment and the Life Course." Body \& Society 11 (2): 41-57.

Jonker, Gerdien. 1997. "Death, Gender, and Memory: Remembering Loss and Burial as a Migrant." In Death, Gender, and Ethnicity, edited by David Field, Jennifer Lorna Hockey, and Neil Small, 187-201. New York, NY: Routledge.

Kephart, William M. 1950. "Status After Death." American Sociological Review 15 (5): 635-643.

Klass, Dennis, Phyllis R. Silverman, and Steven L. Nickman, eds. 1996. Continuing Bonds: New Understandings of Grief, Washington: Taylor \& Francis.

Klein, Jill G., Tina M. Lowrey, and Cele C. Otnes. 2015. "Identity-Based Motivations and Anticipated Reckoning: Contributions to Gift-Giving Theory from an Identity-Stripping Context." Journal of Consumer Psychology 25 (3): 431-448.

Kozinets, Robert V. 2002. "The Field Behind the Screen: Using Netnography for Marketing Research in Online Communities." Journal of Marketing Research 39 (1): 61-72.

Kozinets, Robert V. 2009. Netnography: Doing Ethnographic Research Online. Thousand Oaks, CA: Sage.

Lastovicka, John, and Karen Fernandez. 2005. "Three Paths to Disposition: The Movement of Meaningful Possessions to Strangers." Journal of Consumer Research 31 (4): 813-823.

Lastovicka, John, and Karen Fernandez. 2006. "Extending Generalizations about the Disposition of Meaningful Possessions to Buyers with a Shared Self." In AP Asia-Pacific Advances in Consumer Research, edited by Margaret Craig Lees, 
Teresa Davis, and Gary Gregory, 7: 105-107. Sydney, Australia: Association for Consumer Research.

Levy, Sidney J. 2015. "Olio and Integraphy as Method and the Consumption of Death." Consumption Markets \& Culture. 18(2): 133-154.

Lowrey, Tina M., Cele Otnes, and Kevin Robbins. 1996. "Values Influencing Christmas Gift Giving: An Interpretive Study." In Gift Giving: A Research Anthology, edited by Cele Otnes and Richard F. Beltramini, 37-56. Bowling Green, OH: Bowling Green State University Popular Press.

Lowrey, Tina M., Cele C. Otnes, and Julie A. Ruth. 2004. "Social Influences on Dyadic Giving over Time: A Taxonomy from the Giver's Perspective." Journal of Consumer Research 30 (4): 547-58.

Marcoux, Jean-Sébastien. 2009. "Escaping the Gift Economy." Journal of Consumer Research 36 (4): 671-685.

Markus, Hazel, and Paula Nurius. 1986. "Possible Selves." American Psychologist 41 (9): 954-69.

Mauss, Marcel. 1954. The Gift: Forms and Functions of Exchange in Archaic Societies. Glencoe, IL: The Free Press.

McGrath, Mary Ann, and Basil Englis. 1996. "Intergenerational Gift Giving in Subcultural Wedding Celebrations: The Ritual Audience as Cash Cow." In Gift Giving: A Research Anthology, edited by Cele Otnes and Richard F. Beltramini, 123-141. Bowling Green, OH: Bowling Green State University Popular Press.

Mental Health America. 2008. Coping with Bereavement. http://www.mentalhealthamerica.net/go/information/get-info/grief-andbereavement/coping-with-loss/coping-with-loss.

Mehta, Raj, and Russell W. Belk 1991. "Artifacts, Identity and Transition: Favorite Possessions of Indians and Indian Immigrants to the United States." Journal of Consumer Research 17 (4): 398-411.

Metcalf, Peter, and Richard Huntington. 1991. Celebrations of Death: The Anthropology of Mortuary Ritual. Cambridge University Press.

Mick, David Glenn. 1996. "Self-Gifts." In Gift Giving: A Research Anthology, ed. Cele Otnes and Richard F. Beltramini, 99-120. Bowling Green, OH: Bowling Green State University Popular Press.

Mick, David Glen, and Michelle DeMoss. 1990. "Self-Gifts: Phenomenological Insights from Four Contexts." Journal of Consumer Research 17 (3): 322-332.

Mick, David Glen, and Michelle DeMoss. 1992. "Further Findings on Self-Gifts: Products, Qualities, and Socioeconomic Correlates." In Advances in Consumer Research, edited by John F. Sherry, Jr. and Brian Sternthal, 19: 140-146. Provo: Association for Consumer Research. 
Mitchell, Lisa M., Peter H. Stephenson, Susan Cadell, and Mary Ellen Macdonald. 2012. "Death and Grief On-line: Virtual Memorialization and Changing Concepts of Childhood Death and Parental Bereavement on the Internet." Health Sociology Review 21(4): 413-431.

O'Donohoe, Stephanie, and Darach Turley. 2005. "Till Death Do Us Part? Consumption and the Negotiation of Relationships Following a Bereavement." In Advances in Consumer Research, edited by Geeta Menon and Akshay R. Rao, 32: 625-626. Duluth, MN: Association for Consumer Research.

Otnes, Cele C., and Tina M. Lowrey. 2004. Contemporary Consumption Rituals: A Research Anthology. Mahwah, NJ: Lawrence Erlbaum Associates.

Parkin, David J. 1999. "Mementoes as Transitional Objects in Human Displacement." Journal of Material Culture 4 (3): 303-320.

Paton, Nathalie, and Julien Figeac. 2015. "Muddled Boundaries of Digital Shrines." Popular Communication 13 (4): 251-271.

Pearson, Michael Parker. 1999. The Archaeology of Death and Burial. Phoenix Mill, UK: Sutton.

Price, Linda L., Eric J. Arnould, and Carolyn Folkman Curasi. 2000. "Older Consumers' Disposition of Special Possessions." Journal of Consumer Research 27 (2), 179201.

Radford, Scott K., and Peter H. Bloch. 2015. "Ritual Mythology and Consumption after a Celebrity Death." In Death in a Consumer Culture, edited by Susan Dobscha, 108-122. New York, NY: Routledge.

Reimers, Eva. 1999. "Death and Identity: Graves and Funerals as Cultural Communication." Mortality 4 (2): 147-166.

Riches, Gordon, and Pamela Dawson. 1998. "Lost Children, Living Memories: The Role of Photographs in the Process of Grief and Adjustment among Bereaved Parent." Death Studies 22 (2): 121-140.

Riemer, Jack. 1995. Wrestling with the Angel: Jewish Insights on Death and Mourning. New York City: Schocken Books

Roster, Catherine A. 2014. "The Art of Letting Go: Creating Dispossession Paths toward an Unextended Self." Consumption Markets \& Culture 17 (4): 321-345.

Rubin, Simon Shimshon. 1993. "The Death of a Child is Forever: The Life Course Impact of Child Loss." In Handbook of Bereavement: Theory, Research, and Intervention, edited by Margaret S. Stroebe, Wolfgang Stroebe, and Robert O. Hansson, 285-299. New York, NY: Cambridge University Press.

Ruth, Julie A., Cele C. Otnes, and Frédéric F. Brunel. 1999. "Gift Receipt and the Reformulation of Interpersonal Relationships." Journal of Consumer Research 25 (4): 385-402.

Sahlins, Marshall. 1972. Stone Age Economics. Chicago, IL: Aldine-Atherton. 
Schouten, John W. 1991. "Selves in Transition: Symbolic Consumption in Personal Rites of Passage and Identity Reconstruction." Journal of Consumer Research 17 (4): 412-425.

Sherry, John F., Jr. 1983. "Gift Giving in Anthropological Perspective." Journal of Consumer Research 10 (2): 157-168.

Shurmer, Pamela. 1971. "The Gift Game." New Society, 18 (482): 1242-1244.

Stroebe, Margeret S., Robert O. Hansson, Wolfgang Stroebe, and Henk Schut. 2001. Handbook of Bereavement Research: Consequences, Coping, and Care. Washington, DC: American Psychological Association.

Stroebe, Margaret, and Henk Schut. 1999. "The Dual Process Model of Coping with Bereavement: Rationale and Description." Death Studies 23 (3): 197-224.

Thursby, Jacqueline S. 2006. Funeral Festivals in America. Lexington, KY: The University Press of Kentucky.

Turley, Darach, and Stephanie O'Donohoe. 2012. "The Sadness of Lives And The Comfort Of Things: Goods As Evocative Objects In Bereavement." Journal of Marketing Management 28 (11-12): 1331-1353.

Valentine, Christine A. 2008. Bereavement Narratives. London: Routledge. van Gennep, Arnold. 1960. The Rites of Passage. Chicago, IL: University of Chicago Press.

Vézina, Jean, Paul Bourque, and Yvon Bélanger. 1988. "Spousal Loss: Depression, Anxiety and Well-Being after Grief Periods of Varying Lengths." Canadian Journal on Aging 7 (4): 391-396.

Vickio, Craig J. 1999. "Together in Spirit; Keeping our Relationships Alive When Loved Ones Die." Death Studies 23(2): 161-175.

Weinberger, Michelle F., and Melanie Wallendorf. 2012. "Intracommunity Gifting at the Intersection of Contemporary Moral and Market Economies." Journal of Consumer Research 39(1): 74-92.

Winzelberg, David. 1998. "Cemetery Bans Mementos on Child Graves," available at: http://www.nytimes.com/1998/11/22/nyregion/cemetery-bans-mementos-onchild-graves.html, accessed 28 September 2016.

Wolcott, Harry. 1994. Transforming Qualitative Data: Description, Analysis, and Interpretation. Thousand Oaks, CA: Sage. 
Figure 1. Examples of Gravesite Photographs*
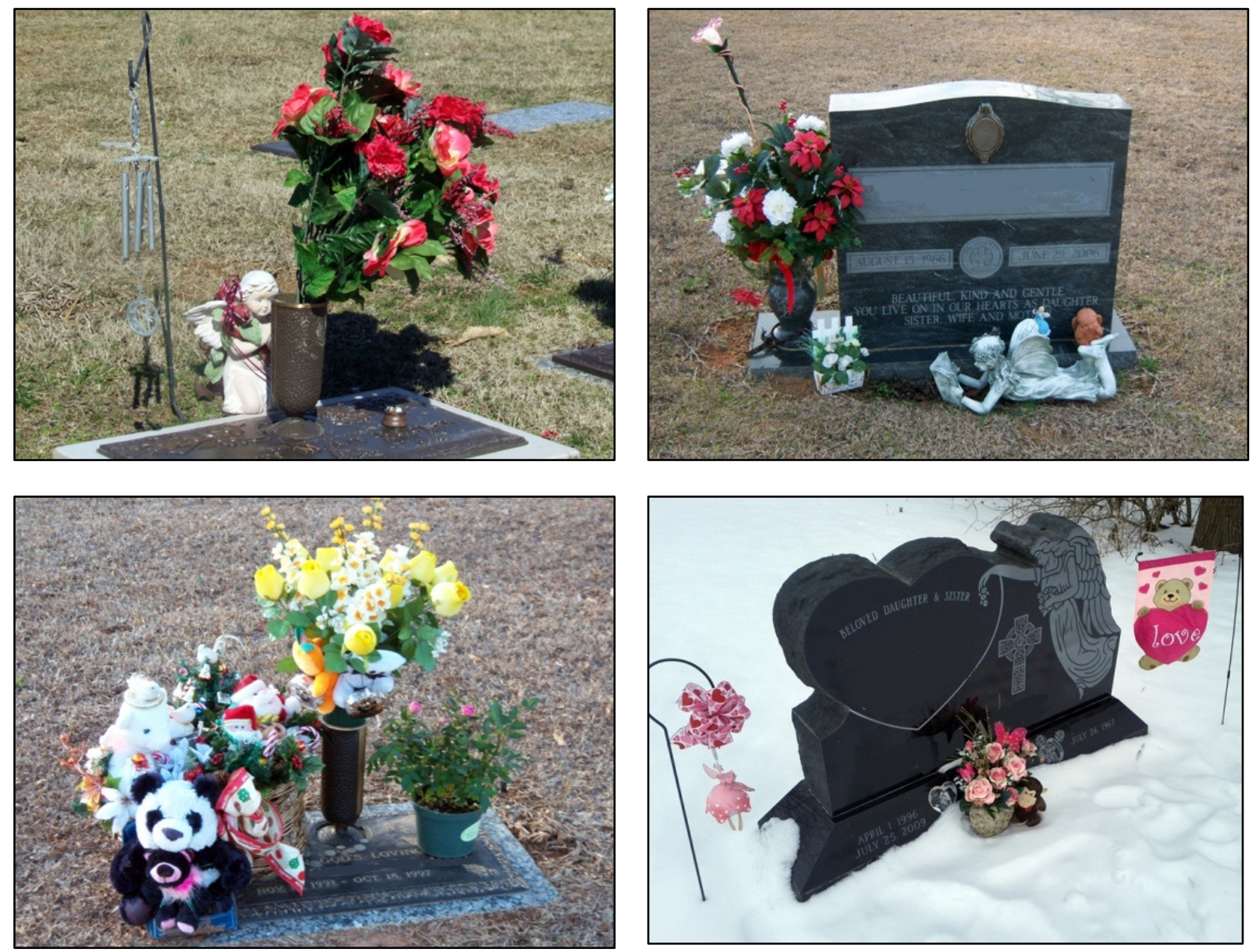

*Names on headstones have been removed. 
Figure 2. Example of Individual Gravesite Over Time*
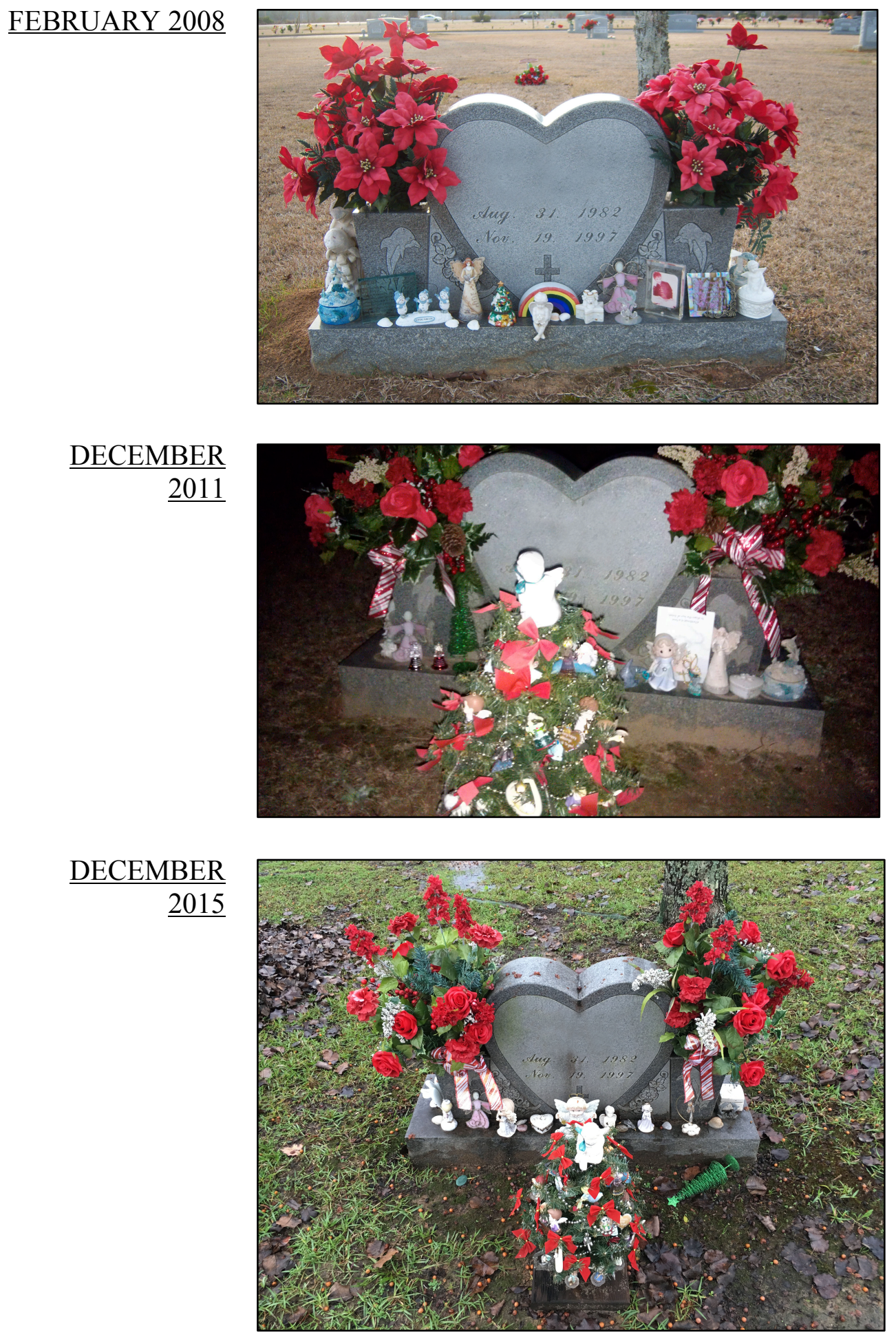

* Name on headstone has been removed. 
Table 1. Materiality in Restorative Giving to the Deceased by Category
MATERIAL
CATEGORY
\&
DEFINITION

\section{IDENTITY ORIENTATION}

\section{EXEMPLARY QUOTE}
PRIMARY
EXTERNAL INFLUENCES

\section{Characteristic}

Characteristic gifts reflect the personal interests or lifestyles, of the deceased. They provide mourners an avenue to remember the deceased through activities or items that they enjoyed.

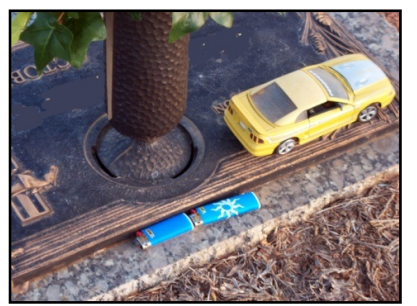

Highly relational; specific to the gift recipient's identity or the identity of the giver; personalized based on knowledge of the deceased consumer
If you visit the cemetery in Lexington Virginia, now called the

Stonewall Jackson Memorial Cemetery I believe, it is not uncommon to find a lemon or two at Jackson't grave. Legend has it that Thomas $J$.

liked to suck on lemons before going into battle. Sorry I don't have a picture to share, but there were two lemons on the grave the last time I was there.

(Posted by Jack, 2008)
Temporal Delimiters

- Experiential Continutity

- Chronological Age

- Time Elaspsed

Social Factors

- Social Exchange

\section{Connective}

Connective gifts to the deceased represent an active exchange between the living and the deceased. These forms of tangible correspondence offer media through which "survivors" may feel they can communicate and connect with their lost loved ones.

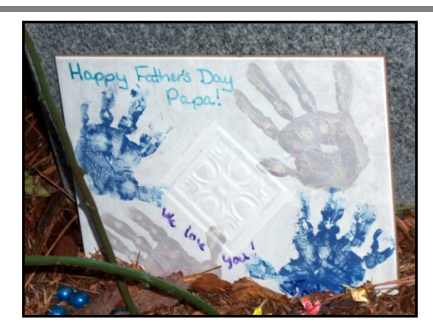

Relational; focuses on relationship affirmation and attempts to strengthen personal bonds, even in the face of death

\author{
... One day, at the \\ height of grief, I wrote a \\ note to my father and \\ tucked it under the lip of \\ his grave marker, \\ thinking that somehow \\ he could "read" it. \\ People in grief just still \\ want some kind of \\ physical connection to \\ their departed loved \\ ones (Posted by \\ Heather, 2007)
}

Temporal Delimiters

- Experiential Continutity

- Time Elaspsed

Social Factors

- Social Exchange

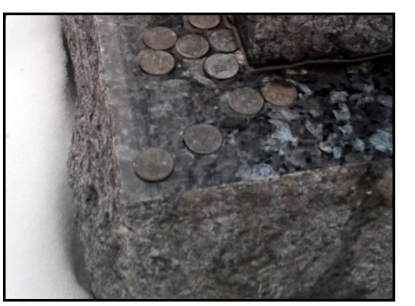

\section{Customary}

Customary gifts to the deceased are driven by traditional holidays or special events. Living friends and family members seek a way to maintain normalcy and adapt to holiday seasons without their deceased loved ones.
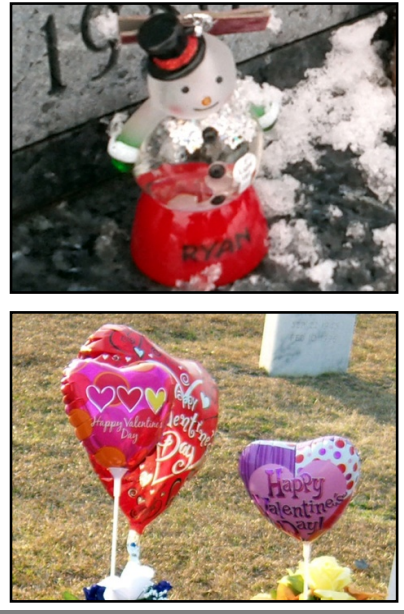

Relational but embedded in the context of cultural identity; focuses on celebrating shared cultural rituals rather than singularizing the deceased individual's identity
During Christmas, we make wreaths from yew boughs, pine cones, and cinnamon sticks. For Halloween, I make a wreath of dried grape vines decorated with miniature pumpkins. (Posted by June, 2006)
Temporal Delimiters

- Experiential Continutity

Social Factors

- Social Comparison

- Collective Responsibility 


\section{Symbolic}

Symbolic material gifts are representative of a larger cultural identity, such as a religious belief system or ideology. May denote beliefs of deceased or act as a symbolic gesture.

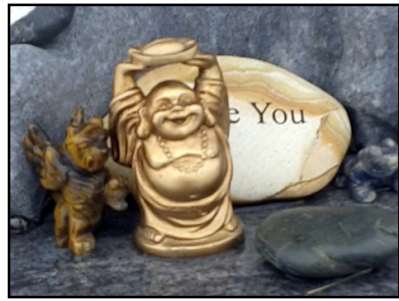

Cultural; reflective of social norms and social identity; symbolically connected to a community

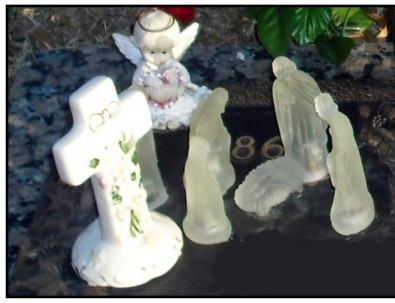

It is true that military folk do sometimes leave special remembrances at the graves of

deceased servicemen

They're called

challenge coins. These tokens identify their

bearers as members of particular units and are prized and cherished by those to whom they've been given. Any challenge coins found at grave sites are almost always certainly left there by comrades-inarms of the deceased. (Posted by Lisa, 2013)
Social Factors

- Social Comparison

- Collective

Responsibility

\section{Decorative}

Decorative gifts merely serve as ornemental pieces to aesthetically "dress up" the gravesite.
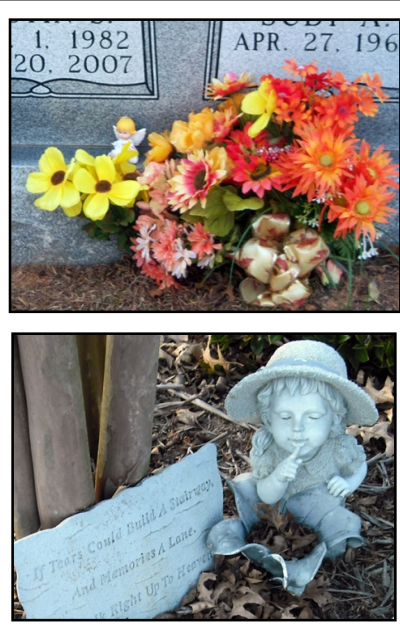

Highly cultural; driven by societal norms, expectations, and aesthetics rather than personalization or customization reflective of the recipient
How nice, I'm sure that your mother smiles at you all the while! I saw a grave in my local cemetery this summer and someone had erected a very small arbor and planted a clematis. It will grow every year and provide beautiful blooms for years and years to come. (Posted by Jennie, 2007)
Social Factors

- Social Comparison

- Collective Responsibility 
Figure 3. Framework for Restorative Giving Practices in Gift Giving to the Deceased

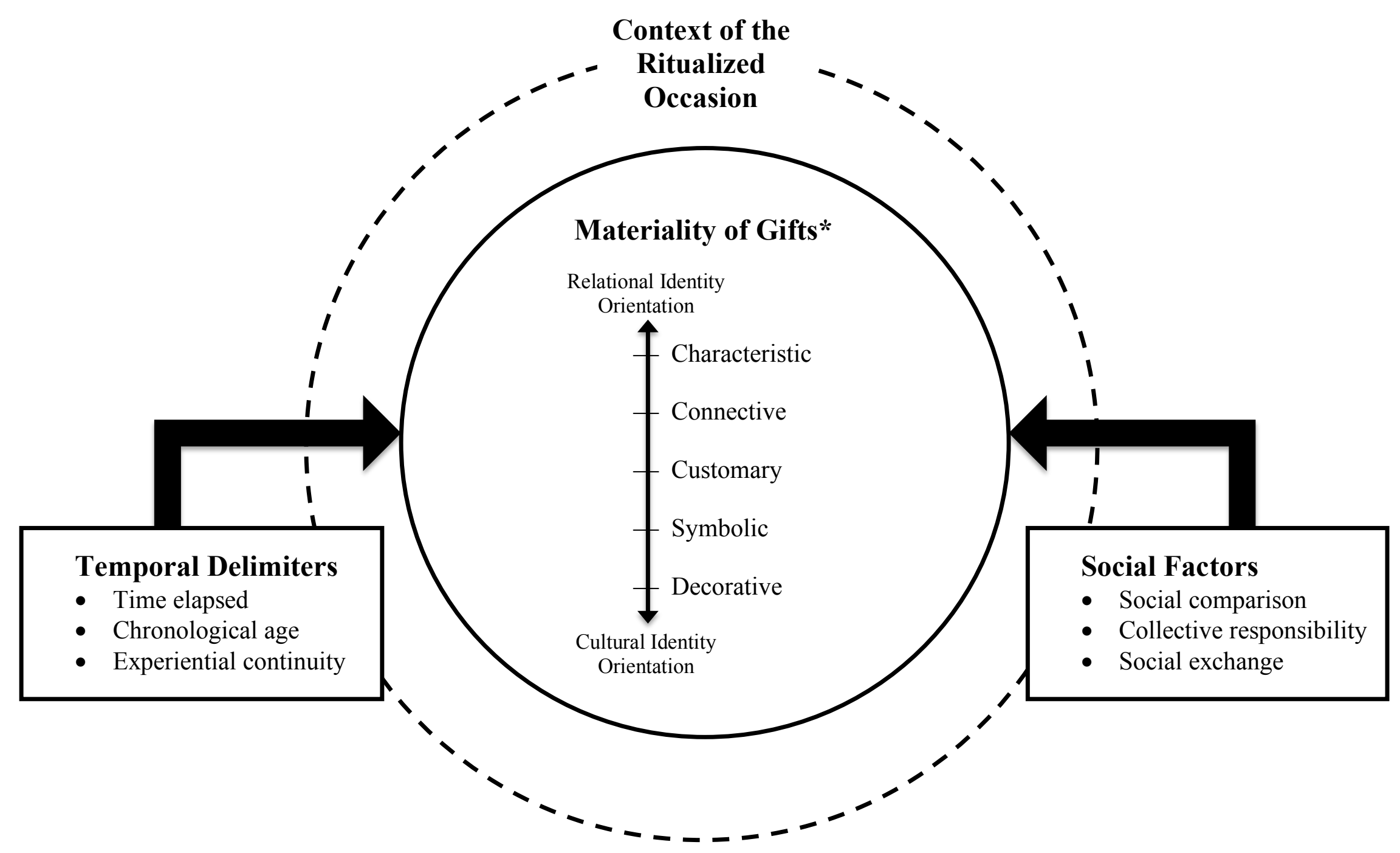

* Material categories are not mutually exclusive. For instance, a decorative gift may also reflect personal characteristics of the deceased. 
Figure 4. Gift Giving and Chronological Age*

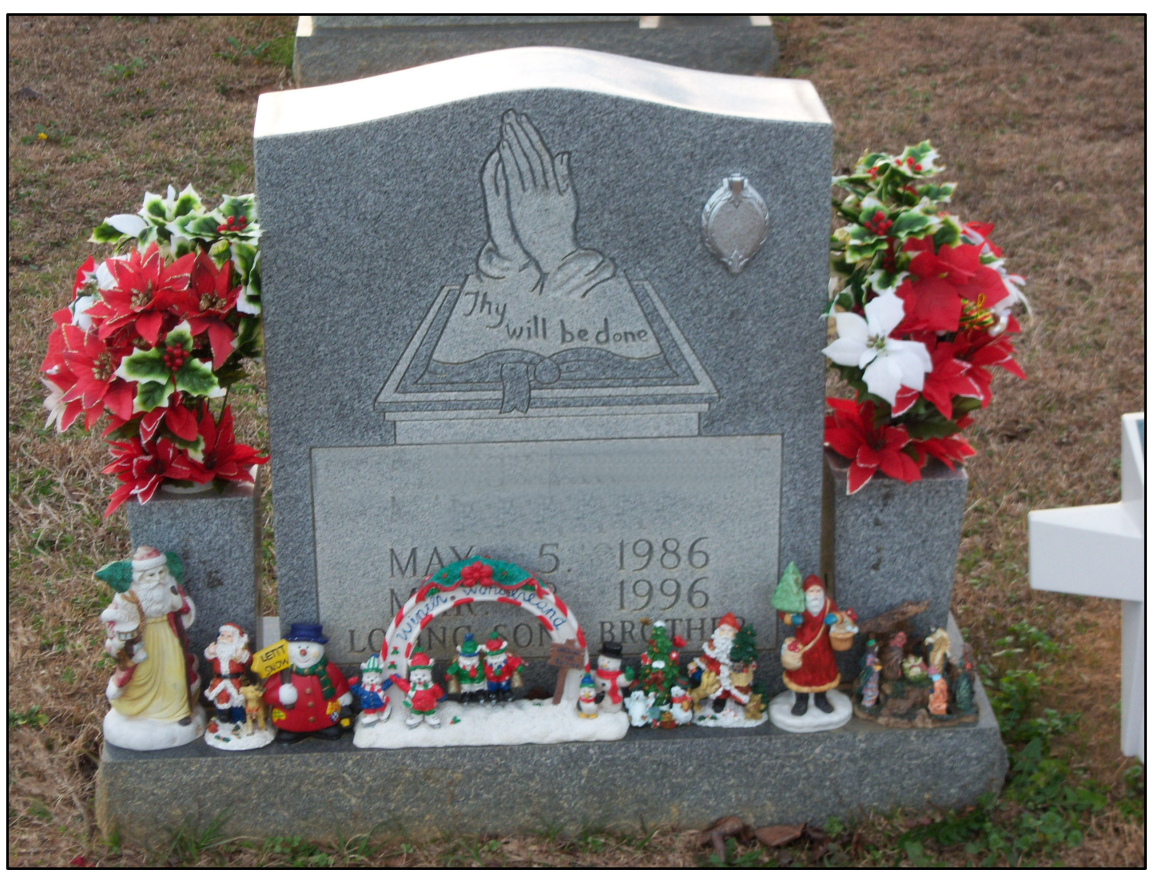

$\underline{\text { Photo taken December } 2008}$

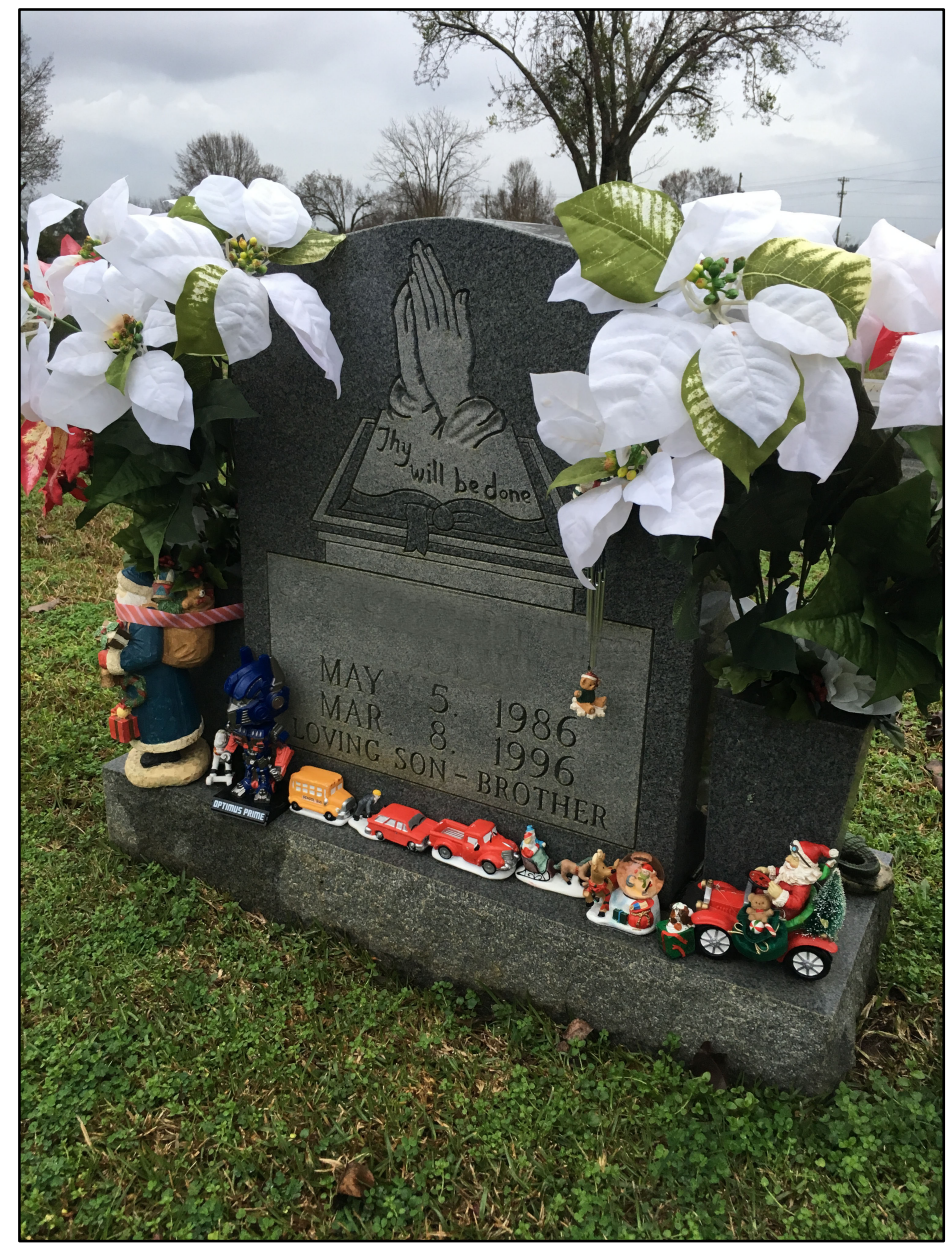

$\underline{\text { Photo taken December } 2015}$

* Name has been removed on the headstones. 
Figure 5. Consumption in the Afterlife

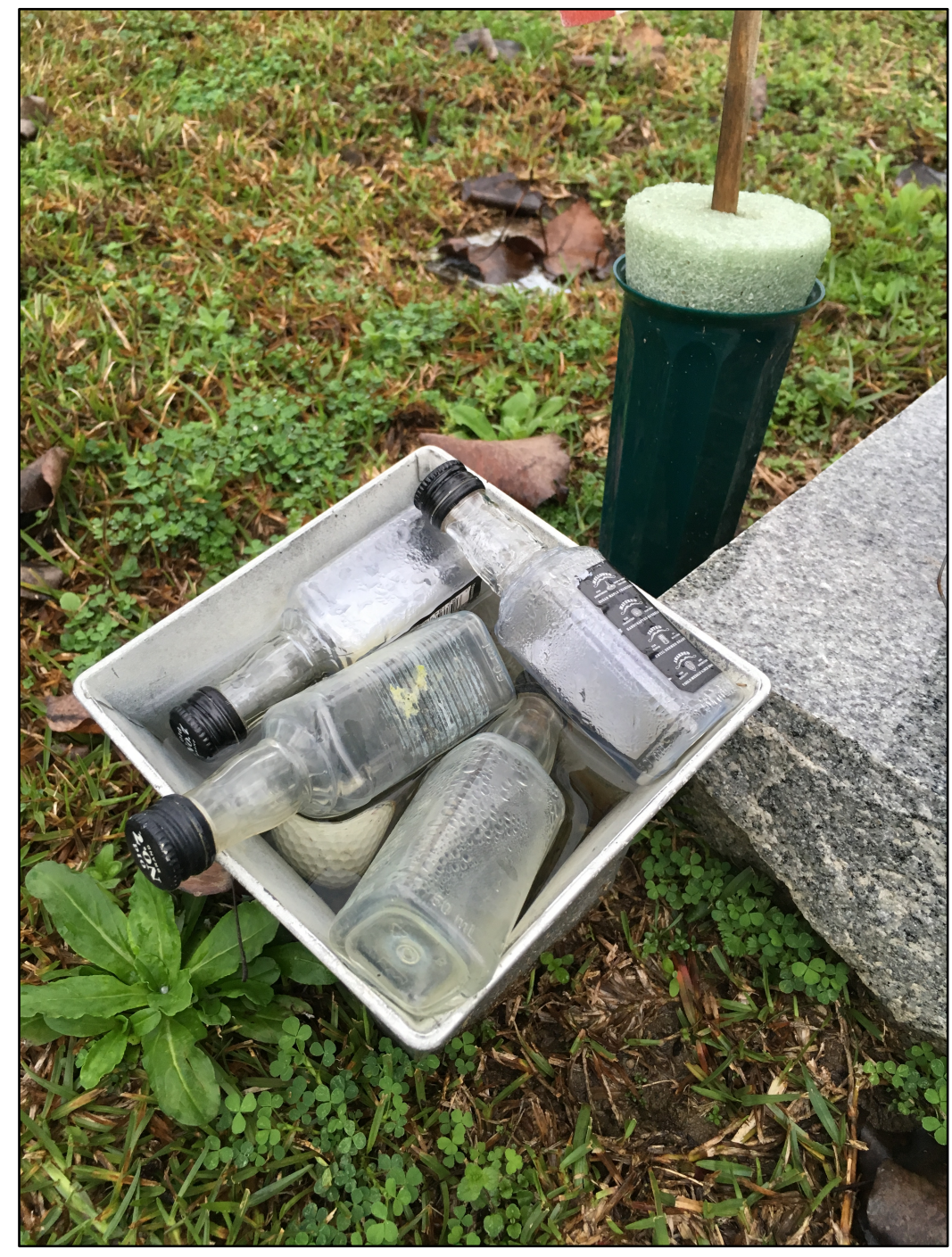

